\title{
OBJETOS DIVERSOS PROCEDENTES DEL POBLADO CALCOLÍTICO DE AMARGUILLO II (LOS MOLARES, SEVILLA)
}

\section{DIVERSE OBJECTS FROM THE CHALCOLITHIC SETTLEMENT OF AMARGUILLO II (LOS MOLARES, SEVILLA)}

\author{
por \\ RosARIO CABRERo GarCía * \\ ANA PAJUELO PANDO ** \\ EZEQUIEL GÓMEZ MURGA *** \\ PEDRO M. LÓPEZ ALDANA ${ }^{* * *}$
}

RESUMEN

\begin{abstract}
Abordamos en este texto el estudio de una serie de objetos del poblado calcolítico de Amarguillo II (Los Molares, Sevilla) procedentes de excavaciones arqueológicas, de prospecciones y de hallazgos casuales que parecen estar relacionados en su mayor parte con el Arte Esquemático Típico. Sus paralelos podemos encontrarlos por diversos ámbitos de la Península Ibérica y por la fachada atlántica europea, principalmente por Bretaña, Escocia e Irlanda.
\end{abstract}

ABSTRACT The text deals to several objects of the calcolithic settlement of Amarguillo II (Los Molares, Sevilla) coming from archaeological excavations, prospections and chance discoveries, which seem to be related with Typical Sketch Art. Similar objects can be found in different places in the Iberian Peninsula and along the European Atlantic front, mainly in Brittany, Scotland and Ireland.

Palabras claves Productos, poblado calcolítico, Arte Esquemático Típico, campiña sevillana.

Key words $\quad$ Product, calcolithic settlement, Typical Sketch Art, sevillana's open land.

* Profesora Titular del Dpto. de Prehistoria y Arqueología de la Universidad de Sevilla. Dirección: C/ Doña María de Padilla s/n, CP 41004 - Sevilla. Telf. 954551411. e-mail: cabrero@us.es

** Licenciada en Prehistoria y Arqueología. Dirección: C/Palma del Río, 24-4B. 41008 -Sevilla. Telf. 954352 479. e-mail: anpando@supercable.es

*** Licenciado en Historia. Universidad de Sevilla. Dirección: C/Castilla la Vieja, 81. CP 41700 - Dos Hermanas (Sevilla). Telf. 954729 594. e-mail: egomezmurga@yahoo.es

**** Licenciado en Prehistoria y Arqueología. Dirección: C/Palma del Río, 24-4B. 41008 -Sevilla. Telf. 954352479 . e-mail: aldanap@supercable.es 


\section{INTRODUCCIÓN}

En el presente texto damos a conocer una serie de objetos encontrados en el poblado de la Edad del Cobre denominado Amarguillo II, que está situado en la provincia de Sevilla, cerca del pueblo actual de Los Molares.

Dos de ellos (los números 9 y 10) han sido hallados como resultado de excavaciones arqueológicas realizadas en él, dentro de dos estructuras circulares diferentes; el resto procede de la recogida de materiales en superficie.

Consideramos que Amarguillo II es un importante yacimiento de la comarca de la campiña sevillana, y tras la prospección arqueológica con sondeos estratigráficos y la excavación arqueológica sistemática efectuada en él (Cabrero 1986; 1987), sabemos que sólo fue ocupado durante el Calcolítico y en un periodo de tiempo no muy dilatado.

En superficie han aparecido algunos materiales que no son calcolíticos (sino modernos, medievales, romanos e ibéricos), pero el porcentaje es mínimo (1\%) respecto a éste (99\%), por lo que aquellos de cronología posterior pudieron ser resultado del paso de otras sociedades por estas tierras, que se asentaron en zonas próximas y de lo cual tenemos numerosas evidencias (Ruiz Delgado 1985).

Los productos arqueológicos recogidos por nosotros en superficie (los números 22,27 y 28 ) son minoría; el resto de las piezas han sido encontradas por vecinos del pueblo, en su mayor parte por Don José Antonio Ramírez López, a quien agradecemos también varios de los dibujos que figuran en este artículo.

Los objetos que hemos reunido aquí para su estudio son muy heterogéneos y bastante desconocidos en sí mismos (nos referimos a su forma, función, etc.). Sabemos que su aportación para el conocimiento histórico de las sociedades calcolíticas de la campiña sevillana y, en consecuencia, de su relación con otras más cercanas, no va a ser muy grande por razones fácilmente deducibles: para ello sería necesario que todo el material procediera de excavaciones arqueológicas bien planificadas, bien realizadas y bien estudiadas, con unas analíticas muy precisas que nos permitieran conocer su lugar en las relaciones objetivas y subjetivas de estas sociedades. Pero no sólo no es posible, sino que, en su mayor parte, se trata de materiales recogidos en superficie, con las evidentes objeciones que eso conlleva. No obstante, pensamos que es preferible reunirlos aquí y darlos a conocer, con todos sus inconvenientes, que no silenciar su conocimiento; consideramos que pueden servir de paralelos para otros que en un futuro puedan presentarse, o abrir algún otro camino en la investigación de las sociedades prehistóricas, de una u otra forma.

Desde luego, tenemos muy claro lo que no queremos, aunque pueda parecerlo. No nos mueve en absoluto el afán de coleccionismo ni nada que recuerde a las teorías sustantivas en sus diferentes versiones encuadradas dentro de la epistemología racionalista, ya sea en su versión original o renovada.

Y sin más preámbulo, nos limitaremos a hacer una ficha de cada una de las piezas, dando su descripción hasta donde nos sea posible. La acompañaremos de un dibujo y añadiremos nuestra opinión personal sobre cada una de ellas, siendo conscientes de lo resbaladizo del terreno que pisamos, pero esperamos que investigaciones futuras lo refuten o confirmen, como es tan frecuente en nuestra disciplina. Incluso, nos aventuramos a asociarlas con el poblado calcolítico, ya que se han encontrado en y sobre el lugar que éste ocupa; convencimiento al que llegamos, más aún, por la implacable destrucción de que está siendo objeto al emplear subsoladoras de un metro de profundidad que perforan y arrasan cada año el yacimiento al arar la tierra para una nueva siembra. Sirva como ejemplo el hecho de que años atrás podían recogerse en superficie molinos de mano calcolíticos enteros, mientras que ahora éstos salen ya partidos en trozos bastante pequeños. 


\section{SITUACIÓN GEOGRÁFICA (Fig. 1)}

El citado asentamiento de la Edad del Cobre, Amarguillo II, se extiende por los terrenos denominados El Tramposo y El Amarguillo (sobre todo por el primero), que están separados por un camino rural perteneciente antaño también al poblado objeto de nuestro estudio. Se encuentran estas dos fincas muy cercanas a la actual población de Los Molares, de donde sale un camino que conduce al yacimiento, concretamente desde el sector noreste de Los Molares, a cuyo término municipal se adscriben. Estas tierras forman parte de la campiña sevillana que se sitúa en la mitad meridional de la Península Ibérica, en su parte occidental, y en la época cuyo estudio nos ocupa, conocida como Calcolítico, estaban bastante próximas a la bahía existente cerca de la desembocadura del río Guadalquivir, junto a la que se asentaba el poblado de Valencina de la Concepción, de la misma época que el de Amarguillo II y con el que indudablemente tenía fuertes conexiones.

La comarca de La Campiña, desde el punto de vista litológico se caracteriza por la presencia de materiales sedimentarios y calizos de formación fundamentalmente terciaria y cuaternaria. Morfológicamente, La Campiña constituye una penillanura que, además de estar recorrida por tres grandes corrientes de agua (Genil, Corbones y Guadaíra) afluentes del Guadalquivir por su margen izquierda en su curso medio, posee abundantes acuíferos, debido a la naturaleza impermeable de los terrenos, que se alimentan de arroyos y aguas superficiales, como ocurre en el caso específico de Los Molares.

\section{EL POBLADO DE AMARGUILLO II}

Creemos que este asentamiento debió ocupar unas 14 hectáreas de extensión, aunque la dispersión de sus materiales es algo mayor (Figs. 1 y 2); además, si tenemos en cuenta el lugar donde han sido detectados algunos probables monumentos megalíticos, que luego mencionaremos, habría que considerar una superficie bastante más grande asociada a él que, por el momento, queda por precisar hasta que prospecciones y nuevos trabajos de excavación lo confirmen.

Situado en una zona llana, en un lugar intermedio entre el bajo valle del Guadalquivir y las primeras estribaciones de las serranías subbéticas, su función fue eminentemente agrícola, como sugiere la feracidad de las tierras donde se asienta, además de la abundancia manifiesta de molinos de mano y moletas, junto con otros datos que expondremos más ampliamente en otro lugar; aunque también fue en cierto modo ganadero, ejerciendo un probable control de la trasterminancia en la zona, o beneficiándose de alguna manera de ella.

Para su mejor conocimiento temporal, disponemos de dos dataciones absolutas (Cabrero et alii 1993) obtenidas por una parte del análisis del colágeno de los huesos de una mujer enterrada en una fosa del poblado, y otra, del carbono del interior de una escoria de cobre procedente de un área metalúrgica de éste, ambos pertenecientes a un mismo momento de ocupación del yacimiento. El primero de los análisis radiocarbónicos fue realizado en el laboratorio Beta Analitic Inc. (Miami, USA) y dio la fecha $4070 \pm 60 \mathrm{BP}(2770-2460$ a.n.e.). El segundo se hizo en The Research Laboratory for Archaeology, Radiocarbon Accelerator Unit, Oxford University (Hedges et alii 1995: 206), proporcionando la fecha $4030 \pm 65$ BP (2870-2409 a.n.e.) ${ }^{1}$. Las características básicas del suelo que envuelve a los restos óseos de nuestra zona, han propiciado que éstos no se hayan visto sometidos a la fuerte degradación química que se ha puesto de manifiesto en suelos con un pH más ácido que, llegando con mayor facilidad al interior del hueso, parece provocar una gran alteración radiocarbónica del colágeno (Nieto et alii 2002: 189-192). No en vano, los restos óseos de Cañada Real han sido puestos como ejemplo de muestras muy poco degradadas por los procesos edafoquímicos (Pecero y Guijo 1998: 191-216).

1. Según la hoja de calibración más reciente (INTCAL98) y comparando ambas fechas, calculamos que debieron tener lugar aproximadamente entre 2600-2500 a.n.e. 


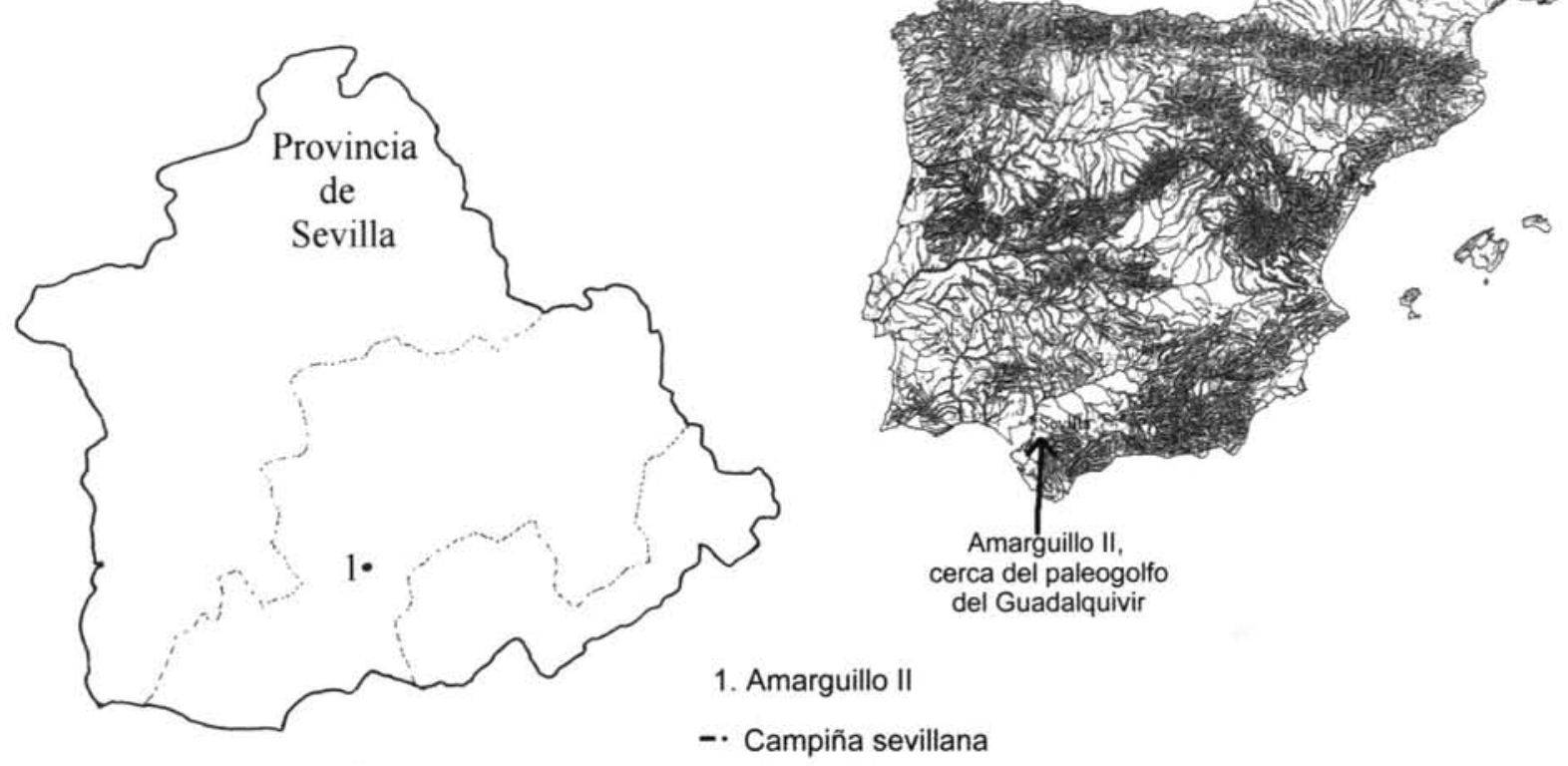

Amarguillo II, extensión aproximada

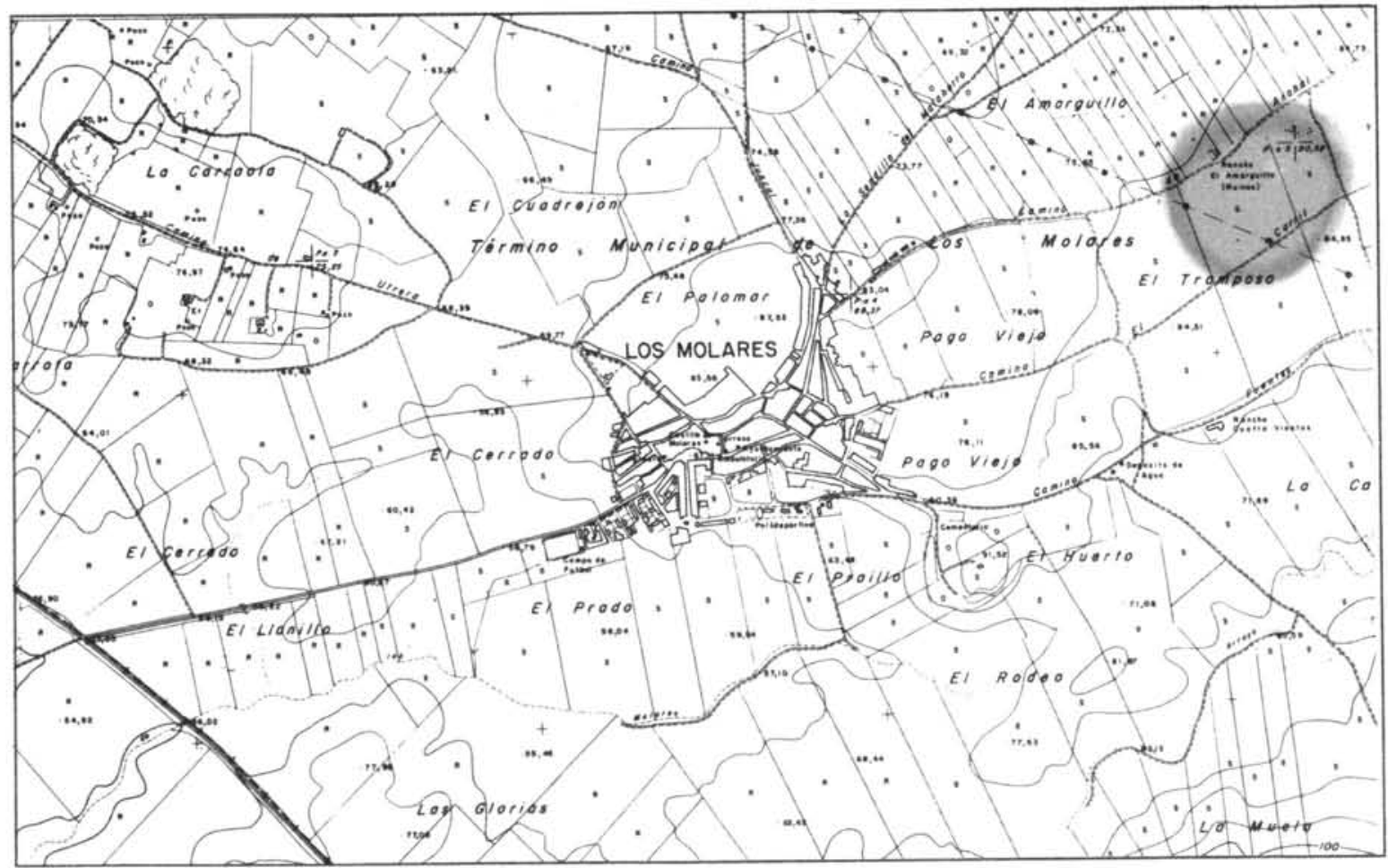

Fig. 1. Situación geográfica 
OBJETOS DIVERSOS PROCEDENTES DEL POBLADO CALCOLÍTICO DE AMARGUILLO II (LOS MOLARES, SEVILLA) 149

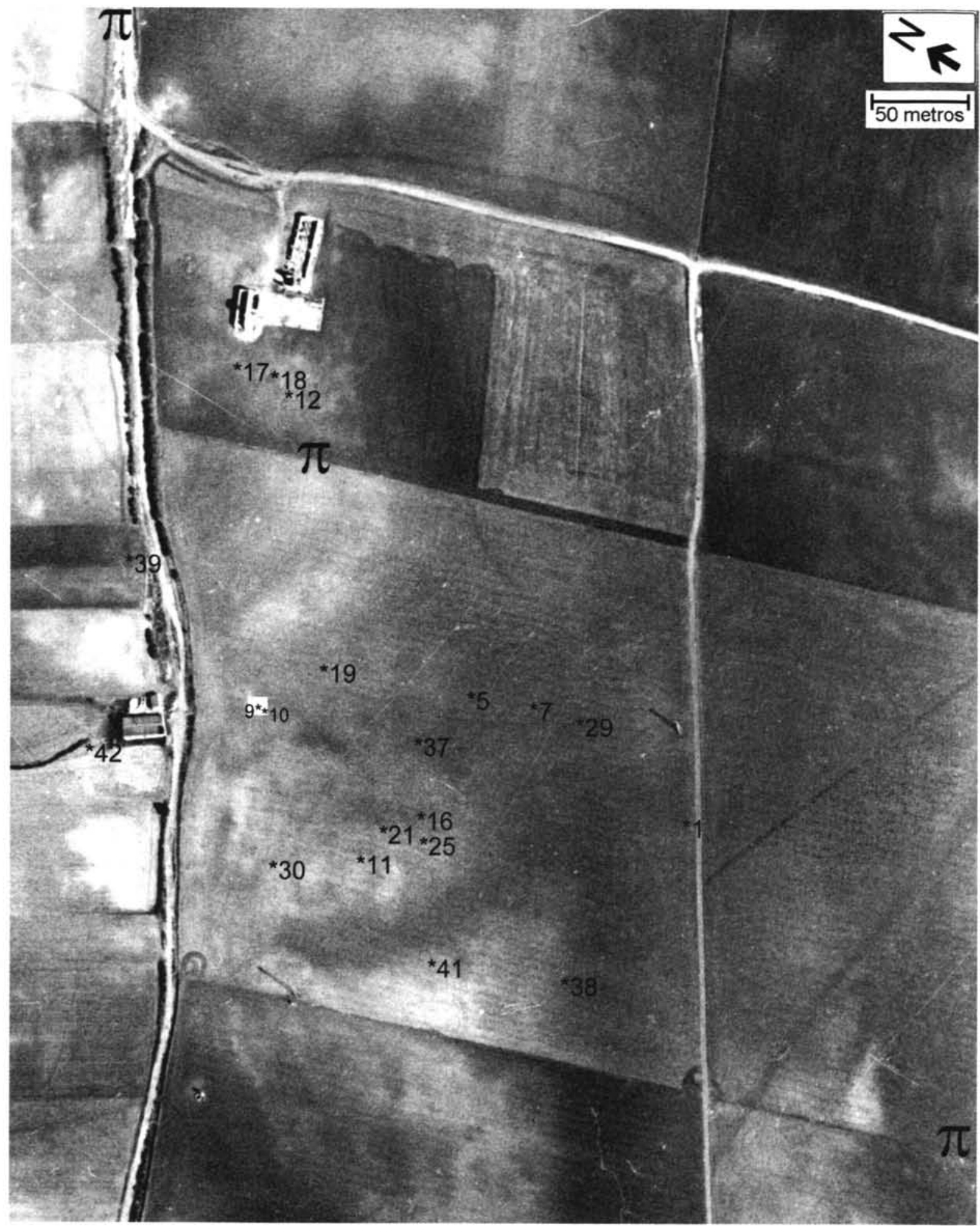

Fig. 2. Fotografía aérea del yacimiento de Amarguillo II. Lugares aproximados de algunos hallazgos y posibles monumentos megalíticos $(\pi)$. 
Existen indicios de tres probables monumentos megalíticos, tanto dentro del poblado como en sus inmediaciones, como puede verse en la fotografía aérea que presentamos, donde también están indicados los lugares aproximados en los que fueron hallados una parte de los productos que damos a conocer en este trabajo.

De poder confirmarse la existencia de monumentos megalíticos, tras su excavación arqueológica, le daría al yacimiento una trascendencia aún mayor, pues no olvidemos que a poco más de 1 kilómetro en línea recta de este lugar, dentro de lo que hoy es el pueblo de Los Molares, había un poblado con una necrópolis de monumentos megalíticos de planta en L (seis descubiertos), con una cronología bastante anterior, obtenida a partir del análisis de restos humanos hallados en el sepulcro conocido como "Dolmen de El Palomar", que ha sido realizada igualmente en el laboratorio Beta Analytic Inc. (Miami, USA) y que es de ${ }^{14} \mathrm{C}: 4930$ \pm 70 BP (3810-3630 a.n.e.) ${ }^{2}$ (Cabrero et alii 1993). Y los materiales encontrados en ellos recuerdan a los del Neolítico de las cuevas andaluzas: ciertas cerámicas, concretamente, guardan bastantes semejanzas con algunas de la Cueva de los Murciélagos de Zuheros (Córdoba) (Cabrero et alii 1996).

Además, igualmente dentro del poblado de Amarguillo II, en la parte excavada, apareció un enterramiento individual en fosa (Cabrero 1986; Cabrero et alii 1993), con lo cual podría hablarse de diferencias de tratamiento en el ritual funerario, contribuyendo a aumentar el interés de este asentamiento.

\section{RELACIÓN DE OBJETOS}

\begin{tabular}{|c|c|c|c|c|c|}
\hline $\mathbf{N}^{\circ} 1$ & & & & & \\
\hline Hallazgo & Amarguillo II & Casual & ficie) -ver plano & & \\
\hline $\begin{array}{l}\text { Descripción y } \\
\text { paralelos }\end{array}$ & $\begin{array}{l}\text { Dos trapecios } \\
\text { dos abultamie }\end{array}$ & $\begin{array}{l}\text { anidos en sus } \\
\text { tos en la par }\end{array}$ & $\begin{array}{l}\text { menores. El infer } \\
\text { arriba. Sección e }\end{array}$ & $\begin{array}{l}\text { mucho más larg } \\
\text { ica. Piedra. }\end{array}$ & que el superior, tiene \\
\hline & $\begin{array}{l}\text { Ídolos tolva o } \\
\text { Ídolos del doln } \\
\text { del Cerro de la } \\
\text { Ídolos bitriang } \\
\text { Representacio } \\
\text { bitrapezoidal }\end{array}$ & $\begin{array}{l}\text { tipo V de Aln } \\
\text { len de Valdeli } \\
\text { Vacas [Trebs } \\
\text { ulares (Ib1) d } \\
\text { nes del dolme } \\
\text { lel ortostato }\end{array}$ & $\begin{array}{l}\text {, sobre todo el } 8 \\
\text { [Zufre (Huelva)] } \\
\text { (Cádiz)] (Álvarez } \\
\text { cares (Bécares } 19 \\
\text { Dombate [Borne } \\
\text { hee 1981: } 143-14\end{array}$ & $\begin{array}{l}\text { s Millares 37] y } \\
\text { omero Bomba 1s } \\
\text { jas 1982: 120), } \\
\text { fig. 2, izquierd } \\
\text { (La Coruña)], s } \\
\text { fig. 16). }\end{array}$ & $\begin{array}{l}9 \text { [Los Millares 16]. } \\
7: 379 \text {, Lám. 1). Ídolo } \\
\text { fusamente decorado. } \\
1^{\circ} \text { de la fila inferior). } \\
\text { re todo con la figura }\end{array}$ \\
\hline Medidas $(\mathrm{cm})$ & long.4,5 & anch. máx. 2 & anch. $\min .1,05$ & gros. máx.1,30 & gros. min. 0,85 \\
\hline Observaciones & $\begin{array}{l}\text { Los paralelos } \\
\text { objetos. Recue } \\
\text { pechos, que n }\end{array}$ & $\begin{array}{l}\text { son muy num } \\
\text { rda a una fig } \\
\text { se da en tod }\end{array}$ & $\begin{array}{l}\text { y damos solo un } \\
\text { squemática feme } \\
\text { ejemplares de e }\end{array}$ & $\begin{array}{l}\text { nuestra, al igual } \\
\text { a, más aún por l } \\
\text { tipo. }\end{array}$ & $\begin{array}{l}\text { e haremos con otros } \\
\text { epresentación de los }\end{array}$ \\
\hline
\end{tabular}

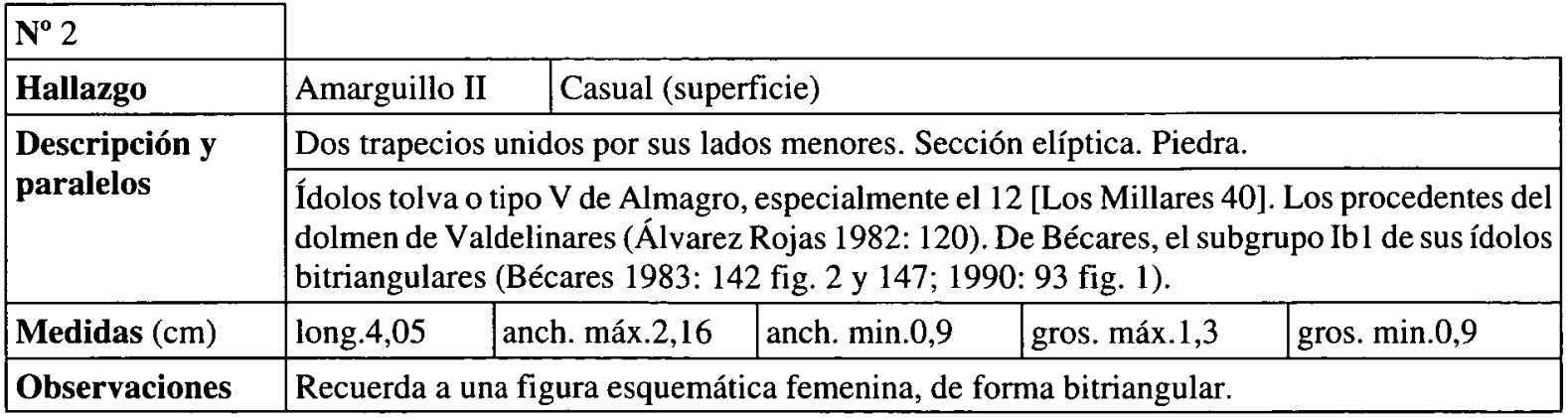

2. Respecto a las características químicas del suelo que envolvía a estos restos óseos, valga el mismo comentario realizado anteriormente para las otras dos dataciones absolutas. 


\begin{tabular}{|c|c|c|c|c|c|}
\hline \multirow{2}{*}{$\begin{array}{l}\mathbf{N}^{0} 3 \\
\text { Hallazgo }\end{array}$} & & & & & \\
\hline & Amarguillo II & \multicolumn{4}{|c|}{ Casual (superficie) } \\
\hline \multirow[t]{2}{*}{$\begin{array}{l}\text { Descripción y } \\
\text { paralelos }\end{array}$} & \multicolumn{5}{|c|}{$\begin{array}{l}\text { Tendente a rectangular con un estrechamiento en el tercio superior. Sección de tendencia cuadrada. } \\
\text { Piedra. }\end{array}$} \\
\hline & \multicolumn{5}{|c|}{ Ídolos-cilindro o tipo IV de Almagro, como el 31 [Los Blanquizares de Lebor (Murcia)]. } \\
\hline Medidas (cm) & long. 3,9 & anch. máx.1,3 & anch. $\min .1$ & gros. máx. & gros. min. \\
\hline Observaciones & \multicolumn{5}{|c|}{$\begin{array}{l}\text { Puede representar una figura humana esquemática, y la zona rebajada que delimita la probable } \\
\text { cabeza sirvió quizá, además, para la suspensión del objeto como colgante. }\end{array}$} \\
\hline
\end{tabular}

\begin{tabular}{|c|c|c|c|c|c|}
\hline \multirow{2}{*}{$\begin{array}{l}N^{\circ} 4 \\
\text { Hallazgo }\end{array}$} & \multirow[b]{2}{*}{ Amarguillo II } & & & & \\
\hline & & \multicolumn{2}{|c|}{ Casual (superficie) } & & \\
\hline \multirow[t]{2}{*}{$\begin{array}{l}\text { Descripción y } \\
\text { paralelos }\end{array}$} & \multicolumn{5}{|c|}{$\begin{array}{l}\text { Producto inacabado, detenido en el proceso de desbaste de la piedra, sin pulimento alguno. } \\
\text { Probable forma bitrapezoidal tendente a bitriangular. Sección elíptica. Piedra. }\end{array}$} \\
\hline & \multicolumn{5}{|l|}{ Ver núm. 2.} \\
\hline Medidas $(\mathrm{cm})$ & long.4,5 & anch. máx.1,8 & anch. $\min .1,26$ & gros. máx.1,36 & gros. min. 1,1 \\
\hline Observaciones & \multicolumn{5}{|c|}{ Evoca a una figura humana esquemática. } \\
\hline
\end{tabular}

\begin{tabular}{|c|c|c|c|c|c|}
\hline \multirow{2}{*}{ Hallazgo } & & & & & \\
\hline & Amarguillo II & \multicolumn{4}{|c|}{ Casual (superficie) -ver plano- } \\
\hline \multirow[t]{2}{*}{$\begin{array}{l}\text { Descripción y } \\
\text { paralelos }\end{array}$} & \multicolumn{5}{|c|}{$\begin{array}{l}\text { Probable forma trapezoidal (el plano superior de la figura no está pulido, pero las características } \\
\text { de su borde nos impide distinguir si se trata o no de fractura). Sección tendente a elíptica. Piedra. }\end{array}$} \\
\hline & \multicolumn{5}{|c|}{$\begin{array}{l}\text { La mitad inferior de la parte conservada es similar al perfil que apreciamos en la figura núm. } \\
2 \text { de nuestro trabajo. }\end{array}$} \\
\hline Medidas (cm) & long. 6,30 & anch. máx.5 & anch. $\min .2,3$ & gros. máx.3,85 & gros. $\min .2,23$ \\
\hline Observaciones & \multicolumn{5}{|c|}{$\begin{array}{l}\text { Si al hacer las analíticas pertinentes resultara estar completa, se trataría de un betilo simple (tipo } \\
\text { III, variante A) de Almagro. En caso contrario, sería como los considerados ídolos tolva por } \\
\text { la misma autora. }\end{array}$} \\
\hline
\end{tabular}

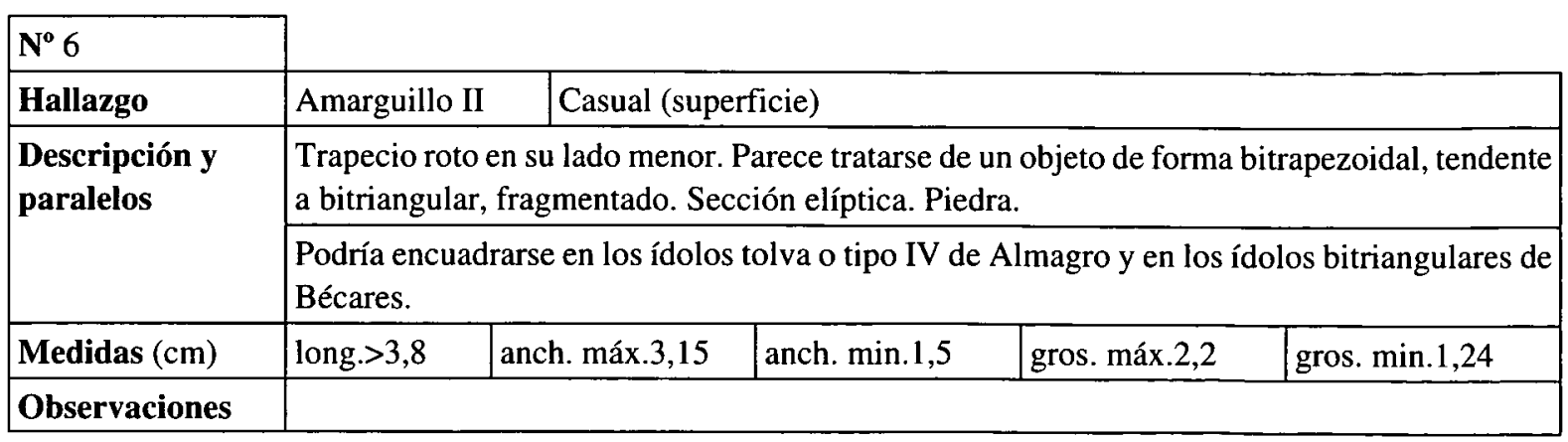




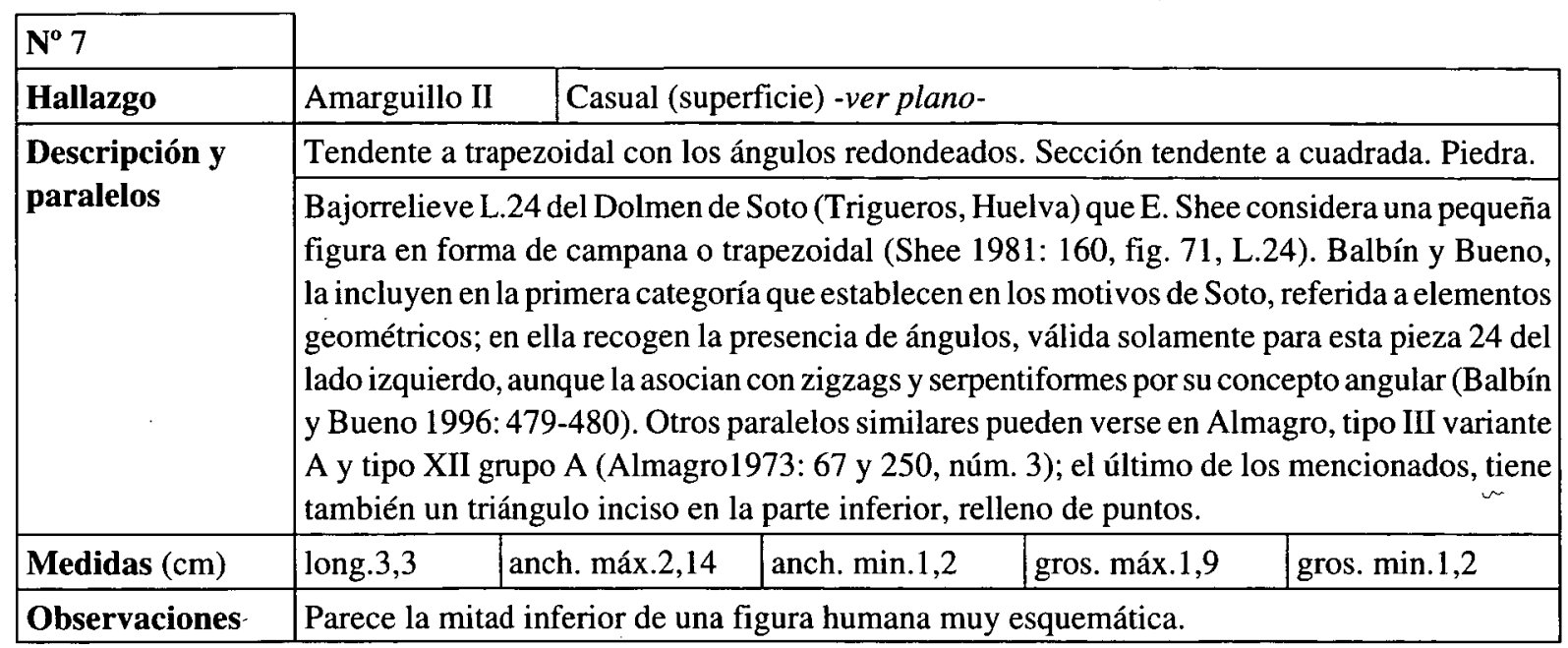

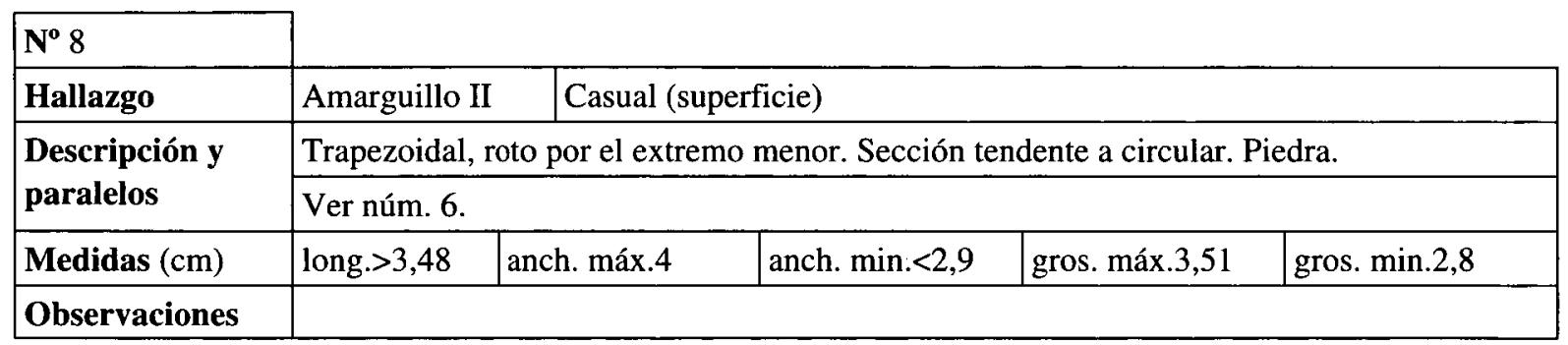

\begin{tabular}{|c|c|c|c|c|c|}
\hline \multirow{2}{*}{$\frac{N^{0} 9}{\text { Hallazgo }}$} & & & & & \\
\hline & Amarguillo II & \multicolumn{4}{|c|}{$\begin{array}{l}\text { Excavación -ver plano-. Se halló en el interior de una cabaña de forma } \\
\text { tendente a circular que medía algo más de } 2 \text { metros de diámetro; tenía una } \\
\text { entrada abierta al oeste y el resto de la estructura estaba excavada } \\
\text { parcialmente en la roca alcoriza de base, a distintas alturas, alcanzando por } \\
\text { un lado los } 76 \mathrm{~cm} \text { mientras que por otro tenía sólo } 18 \mathrm{~cm} \text {. En la pared opuesta } \\
\text { a su entrada se abría otra estructura, también de tendencia circular, de algo } \\
\text { menos de } 1 \mathrm{~m} \text { de diámetro, que sirvió de almacén a la anterior por el depósito } \\
\text { de materiales encontrados en su interior. }\end{array}$} \\
\hline \multirow{2}{*}{$\begin{array}{l}\text { Descripción y } \\
\text { paralelos }\end{array}$} & \multicolumn{5}{|c|}{ Tendente a trapezoidal. Sección tendente a trapezoidal. Cerámica. } \\
\hline & \multicolumn{5}{|c|}{ Ver núm. 7.} \\
\hline Medidas $(\mathrm{cm})$ & long. 2,3 & anch. máx.2,1 & anch. min.1 & gros. máx.1 & gros. min. \\
\hline Observaciones & \multicolumn{5}{|c|}{$\begin{array}{l}\text { En un principio pensábamos que podía tratarse de la mitad inferior de una figurilla ginemórfica, } \\
\text { como las procedentes del poblado de Cabezo Juré [Alosno (Huelva)] (Nocete 2001: fig. 48). } \\
\text { Finalmente, nos percatamos de que no tenía signos visibles de fractura alguna, por lo que habría } \\
\text { que paralelizarla con las formas trapezoidales asociadas al elemento de la ficha núm. 7; si bien } \\
\text { aún no ha sido objeto de ninguna analítica. }\end{array}$} \\
\hline
\end{tabular}




\begin{tabular}{|c|c|c|c|c|c|}
\hline \multirow{2}{*}{$\frac{\mathbf{N}^{\mathbf{0}} 10}{\text { Hallazgo }}$} & \multirow[b]{2}{*}{ Amarguillo II } & & & & \\
\hline & & \multicolumn{4}{|c|}{$\begin{array}{l}\text { Excavación -ver plano-. Procede del interior de una estructura circular, } \\
\text { pequeña, que tenía unos escalones para bajar hasta el fondo de la misma, } \\
\text { y de la cual solamente se excavó una parte, ya que el resto se metía en la } \\
\text { pared sur de una de las cuadrículas delimitadas en la excavación. }\end{array}$} \\
\hline \multirow[t]{2}{*}{$\begin{array}{l}\text { Descripción y } \\
\text { paralelos }\end{array}$} & \multicolumn{5}{|c|}{$\begin{array}{l}\text { Tendente a rectangular con dos escotaduras en el tercio superior. Sección tendente a semicircular } \\
\text { que se va estrechando y aplanando hacia el extremo superior. Hueso parcialmente quemado. }\end{array}$} \\
\hline & \multicolumn{5}{|c|}{$\begin{array}{l}\text { Ídolos cruciformes de tipo II F de Almagro, como el } 12 \text { [Cerro del Real, Galera (Granada)]. } \\
\text { También de Almagro, ídolos-cilindro o tipo IV, como } 31 \text { [Los Blanquizares de Lebor (Murcia)]. } \\
\text { En el monumento megalítico tipo tholos excavado en Huerta Montero [Almendralejo(Badajoz)] } \\
\text { apareció uno muy similar, de piedra; dato que conocemos oralmente por uno de sus excavadores, } \\
\text { F. Blasco Rodríguez, y se da la circunstancia de que se han realizado varias dataciones de }{ }^{4} \mathrm{C} \\
\text { para esta tumba, con dos momentos de ocupación comprendidos entre } 4650 \pm 250 \mathrm{BP} \text { y } 4220 \\
\pm 100 \mathrm{BP} \text { (Blasco Rodríguez y Ortiz Aleson 1991). En el poblado de Papauvas [Aljaraque } \\
\text { (Huelva)] se encontró uno parecido, de pizarra, sobre placa trapezoidal y con dos entalles también } \\
\text { en el tercio superior (Martín de la Cruz 1986: } 60 \text {, fig. 27, 48). }\end{array}$} \\
\hline Medidas (cm) & long.5,3 & anch. máx.1,1 & anch. min. & gros. máx.0,65 & gros. $\min .0,3$ \\
\hline Observaciones & \multicolumn{5}{|c|}{$\begin{array}{l}\text { Parece una figura humana esquemática y guarda bastante semejanza con el que presentamos } \\
\text { en la ficha núm. } 3 \text { de este artículo, si bien es de menor grosor y diferente materia prima. }\end{array}$} \\
\hline
\end{tabular}

\begin{tabular}{|c|c|c|c|c|c|}
\hline \multirow{2}{*}{$\frac{\mathbf{N}^{0} 11}{\text { Hallazgo }}$} & \\
\hline & Amarguillo II & \multicolumn{4}{|c|}{ Casual (superficie) -ver plano- } \\
\hline \multirow{2}{*}{$\begin{array}{l}\text { Descripción y } \\
\text { paralelos }\end{array}$} & \multicolumn{5}{|c|}{ Tres formas tendentes a esféricas fusionadas, la central de mayor tamaño que las laterales. Piedra: } \\
\hline & \multicolumn{5}{|c|}{$\begin{array}{l}\text { Visto lateralmente se asemeja a la estatuilla de esteatita de Campu-Fiurelli (Grossa-Corse) consi- } \\
\text { derada del Neolítico final o Calcolítico (Guilaine 1976: lám. 23, 3). En el sepulcro megalítico de } \\
\text { El Poyato [Encinas Reales (Córdoba)] hay una pieza pequeña, trilobulada, de caliza pulimentada } \\
\text { (Cabrero 1988: 670, fig. 245). Figurillas del hipogeo de Hal Saflieni (Malta), de finales del IV } \\
\text { milenio a.C. (Gimbutas 1996: 165, fig. 255, 1). La estatuilla de Llamoso (Asturias) (Almagro 1973: } \\
\text { 277, lám. XLIV, 2) recuerda, enlíneas generales, a toda la serie "bolas" de nuestro yacimiento. } \\
\text { La representación de motivos trilobulados son frecuentes en la pintura rupestre esquemática } \\
\text { peninsular (Acosta 1968: 87, fig. 25, 1-3). En la tipología establecida por Bécares pertenece } \\
\text { al grupo Bb2, denominado "barras", que se sitúa en el apartado "barras y puntos" (Bécares 1983: } \\
\text { 143, fig. 2; 148). }\end{array}$} \\
\hline Medidas $(\mathrm{cm})$ & long.9,55 & anch. máx.5,15 & anch. $\min .3,75$ & gros. máx.5,7 & gros. $\min .4$ \\
\hline
\end{tabular}




\begin{tabular}{|l|l|}
\hline Observaciones & $\begin{array}{l}\text { Recuerda a una figura femenina esquemática vista tanto frontal como lateralmente. La perspectiva } \\
\text { frontal del producto parece representar parte de la mitad inferior de un cuerpo femenino (pubis } \\
\text { y caderas). El paralelo señalado de Hal Saflieni (Malta), según descripción de M. Gimbutas, } \\
\text { se trataría de un amuleto con la forma de unos glúteos, hallado junto a otras dos figurillas de } \\
\text { terracota -que muestran glúteos aovados- en una cámara subterránea con forma de huevo y } \\
\text { decorada con espirales de serpiente, posiblemente en relación con el poder de la vida o la fertilidad } \\
\text { en el tránsito hacia la muerte (Gimbutas 1996: 165, fig. 255, 1). } \\
\text { Con este producto abrimos un grupo encuadrable tipológicamente en un apartado que los } \\
\text { habitantes del pueblo de Los Molares denominan tradicionalmente "ídolos bolas" o "venus } \\
\text { de bolas". Sobre materias primas muy similares se dan bolas simples -que no hemos incluido } \\
\text { en el presente trabajo- y compuestas; estas últimas de múltiples formas: unas con un cuerpo } \\
\text { mayor del que salen apéndices, otras, bolas geminadas o polilobuladas y, finalmente, otras muchas, } \\
\text { fracturadas por su parte menos gruesa (cuello) y que han quedado por ello individualizadas, } \\
\text { impidiéndonos conocer su forma completa. }\end{array}$ \\
\hline
\end{tabular}

\begin{tabular}{|c|c|c|c|c|c|}
\hline \multirow{2}{*}{$\begin{array}{l}\mathbf{N}^{\mathbf{0}} 12 \\
\text { Hallazgo }\end{array}$} & \multirow[b]{2}{*}{ Amarguillo II } & \multirow{2}{*}{\multicolumn{2}{|c|}{ Casual (superficie) -ver plano }} & & \\
\hline & & & & & \\
\hline \multirow[t]{2}{*}{$\begin{array}{l}\text { Descripción y } \\
\text { paralelos }\end{array}$} & \multicolumn{5}{|c|}{$\begin{array}{l}\text { Forma oval de mayor tamaño de la que salen dos apéndices tendentes a esféricos, menores. } \\
\text { Piedra }\end{array}$} \\
\hline & \multicolumn{5}{|c|}{$\begin{array}{l}\text { Como paralelos remotos citamos las carved stone balls }{ }^{3} \text { escocesas (Marshall 1976-7: 40-72) } \\
\text { el posible ídolo Calcolítico de Lebrija citado por Caro Bellido (Caro Bellido 1982-1983: 49, } \\
\text { láms. 2-3) y la estatuilla de Llamoso (Almagro 1973: 277, lám. XLIV, 2). }\end{array}$} \\
\hline Medidas $(\mathrm{cm})$ & long. 8,84 & anch. máx.8,92 & anch. $\min .3,1$ & gros. máx.6 & gros. min. 3,62 \\
\hline Observaciones & \multicolumn{5}{|c|}{$\begin{array}{l}\text { Probable esquematización de una figura humana femenina donde resaltan, sobre todo, dos bolas } \\
\text { a modo de pechos. Aunque no podemos ponerlo como ejemplo de paralelo exacto, pues sus } \\
\text { diferencias son marcadas, en cierto modo este número 12, denominado por su descubridor-J. A. } \\
\text { Ramírez López-como Tramposilla II, y otros del grupo bolas antes mencionado, podrían guardar } \\
\text { cierta relación con un objeto de Lebrija considerado ídolo del Calcolítico(Caro Bellido 1982-1983: } \\
\text { 49, láms. 2-3). Además, a nosotros nos recuerda también algo a las bolas de piedra encontradas } \\
\text { en Escocia, especialmente concentradas en Aberdeenshire (Powell 1966: 110-113); algunos } \\
\text { ejemplares han sido hallados en Skara Brae (Orkney Islands) y fechadas allí entre 3200-2500 } \\
\text { BC, en el Neolítico tardío (Marshall 1976-7: 62; Shee 1997: 377-389). La verdad es que estos } \\
\text { objetos son mucho más elaborados que los de Amarguillo III, con formas más simétricas y esmeradas } \\
\text { decoraciones, que recuerdan a las de muchos monumentos megalíticos del Reino Unido e Irlanda; } \\
\text { pero quede aquí la cita, aunque se trate sólo de un eco lejano, de unas piezas cuya finalidad } \\
\text { se desconoce, pero que han sido consideradas como símbolos probables de estatus (Marshall } \\
\text { 1976-7: 62-64) o quizás amuletos (Gimbutas 1996: 82, fig. 131), entre otras interpretaciones. }\end{array}$} \\
\hline
\end{tabular}

3. Hay más de 400 bolas de piedra conocidas en Escocia con la denominación común de "carved stone balls". 


\begin{tabular}{|c|c|c|c|c|c|}
\hline \multirow{2}{*}{$\begin{array}{l}\mathrm{N}^{\circ} 13 \\
\text { Hallazgo }\end{array}$} & & & & & \\
\hline & Amarguillo II & \multicolumn{4}{|c|}{ Casual (superficie) } \\
\hline \multirow[t]{2}{*}{$\begin{array}{l}\text { Descripción y } \\
\text { paralelos }\end{array}$} & \multicolumn{5}{|c|}{$\begin{array}{l}\text { Dos formas tendentes a esféricas unidas. Presenta incisiones por el contomo de una de sus caras. } \\
\text { Piedra. }\end{array}$} \\
\hline & \multicolumn{5}{|c|}{$\begin{array}{l}\text { Ídolos tipo I o Tipo el Garcel, variante A de Almagro (Almagro 1973: fig. I), sobre todo el } 3 \\
\text { en pintura esquemática a los que P. Acosta llama Halteriforme B debido a la reducción a los } \\
\text { discos elementales más o menos circulares, por pérdida de la barra central (Acosta 1968: } 82 \\
\text { fig. 24, 3-4). J. Bécares los adscribe al grupo de los ídolos bitriángulares, Ib, y da un paralelo } \\
\text { exacto por su forma a éste que aquí presentamos en el bilobulado que aparece el último de la } \\
\text { parte central de la figura } 2 \text {, a la derecha (Bécares } 1990: 93 \text { y 94, fig. } 2 ; 1983: 143 \text {, fig. } 2 ; 147 \text { ) }\end{array}$} \\
\hline Medidas $(\mathrm{cm})$ & long. 6,13 & anch. máx.3,4 & anch. $\min .2,45$ & gros. máx. & gros. min. \\
\hline Observaciones & \multicolumn{5}{|c|}{$\begin{array}{l}\text { Se asemeja a una figura humana femenina muy esquemática. Los trazos grabados en su contorno } \\
\text { podrían indicar un manto que cubre de cabeza a pies o tal vez señalan pelo y vestido. }\end{array}$} \\
\hline
\end{tabular}

\begin{tabular}{|c|c|c|c|c|c|}
\hline \multirow{2}{*}{$\begin{array}{l}\text { No } 14 \\
\text { Hallazgo }\end{array}$} & & & & & \\
\hline & Amarguillo II & \multicolumn{4}{|c|}{ Casual (superficie) } \\
\hline \multirow[t]{2}{*}{$\begin{array}{l}\text { Descripción y } \\
\text { paralelos }\end{array}$} & \multicolumn{5}{|c|}{$\begin{array}{l}\text { Tendente a esférica pero con base algo achatada. Inicio de otra forma, presumiblemente esférica } \\
\text { también, y desplazada hacia un lado con respecto al eje que forma la base. Fracturado. Piedra. }\end{array}$} \\
\hline & \multicolumn{5}{|l|}{ Ver núm. 11.} \\
\hline Medidas (cm) & long. $>6$ & anch. máx.5,4 & anch. min. & gros. máx. & gros. min. \\
\hline Observaciones & & & & & \\
\hline
\end{tabular}

\begin{tabular}{|c|c|c|c|c|c|}
\hline \multirow{2}{*}{$\frac{N^{\circ} 15}{\text { Hallazgo }}$} & & & & & \\
\hline & Amarguillo II & \multicolumn{4}{|c|}{ Casual (superficie) } \\
\hline \multirow[t]{2}{*}{$\begin{array}{l}\text { Descripción y } \\
\text { paralelos }\end{array}$} & \multicolumn{5}{|c|}{$\begin{array}{l}\text { Tendente a ovoidal, fracturada en el cuello que la uniría al resto de la pieza (el cuello se encuentra } \\
\text { en uno de los lados estrechos). Piedra. }\end{array}$} \\
\hline & \multicolumn{5}{|c|}{$\begin{array}{l}\text { Podría estar relacionado con los motivos halteriformes esquemáticos (Acosta 1968: 82, fig } \\
\text { 24, 1-3; Bueno y Balbín 1992: 550, fig. } 66 \text { arriba) o con los denominados betilos variante } \\
\text { o con cabeza de "alcachofa" (Almagro 1973: 97, fig. 18; lám. L); o incluso asociarse a formas } \\
\text { del tipo del ídolo de Llamoso (Asturias) (Almagro 1973: 277, lám. XLIV, 2). }\end{array}$} \\
\hline Medidas (cm) & long. $>6$ & anch. máx.5 & anch. min. & gros. máx. & gros. min. \\
\hline Observaciones & \multicolumn{5}{|c|}{$\begin{array}{l}\text { Con formas algo disímiles pero respondiendo a una configuración bastante unitaria, vemos } \\
\text { que estos objetos en forma de bolas aparecen reiteradamente en este yacimiento. }\end{array}$} \\
\hline
\end{tabular}

\begin{tabular}{|c|c|c|c|c|c|}
\hline \multirow{2}{*}{$\begin{array}{l}N^{\circ} 16 \\
\text { Hallazgo }\end{array}$} & & & & & \\
\hline & Amarguillo II & \multicolumn{4}{|c|}{ Casual (superficie) -ver plano- } \\
\hline \multirow{2}{*}{$\begin{array}{l}\text { Descripción y } \\
\text { paralelos }\end{array}$} & \multicolumn{5}{|c|}{ Tendente a esférico, roto en lo que podría ser una prolongación o cuello. Piedra. } \\
\hline & \multicolumn{5}{|l|}{ Ver núm. 15.} \\
\hline Medidas $(\mathrm{cm})$ & long. 4,7 & anch. máx.5 & anch. min. & gros. máx. & gros. min. \\
\hline Observaciones & \multicolumn{5}{|c|}{$\begin{array}{l}\text { Aunque en términos generales sirve todo lo indicado para el núm. } 15 \text {, no queremos dejar de } \\
\text { señalar que éste no presenta cuello visible. }\end{array}$} \\
\hline
\end{tabular}




\begin{tabular}{|c|c|c|c|c|c|}
\hline \multirow{2}{*}{$\frac{\mathrm{N}^{\circ} 17}{\text { Hallazgo }}$} & & & & & \\
\hline & Amarguillo II & \multicolumn{4}{|c|}{ Casual (superficie) -ver plano- } \\
\hline \multirow{2}{*}{$\begin{array}{l}\text { Descripción y } \\
\text { paralelos }\end{array}$} & \multicolumn{5}{|c|}{ Tendente a ovoidal, fracturada en la zona de unión al resto de la pieza. Piedra. } \\
\hline & \multicolumn{5}{|c|}{ Ver núm. 15 y 16.} \\
\hline Medidas (cm) & long. $>5,3$ & anch. máx.5 & anch. min. & gros. máx. & gros. min. \\
\hline Observaciones & & & & & \\
\hline
\end{tabular}

\begin{tabular}{|c|c|c|c|c|c|}
\hline \multirow{2}{*}{\begin{tabular}{|l}
$N^{\circ} 18$ \\
Hallazgo
\end{tabular}} & & & & & \\
\hline & Amarguillo II & \multicolumn{4}{|c|}{ Casual (superficie) -ver plano- } \\
\hline \multirow{2}{*}{$\begin{array}{l}\text { Descripción y } \\
\text { paralelos }\end{array}$} & \multicolumn{5}{|c|}{ Tendente a esférica, con dos conexiones (una a cada lado), ambas fracturadas. Piedra } \\
\hline & \multicolumn{5}{|l|}{ Ver núm. 11.} \\
\hline Medidas (cm) & long. $>5,23$ & anch. máx.4,29 & anch. $\min .2,1$ & gros. máx. & gros. min. \\
\hline Observaciones & \multicolumn{5}{|c|}{ Este producto debió ser trilobulado (al menos). } \\
\hline
\end{tabular}

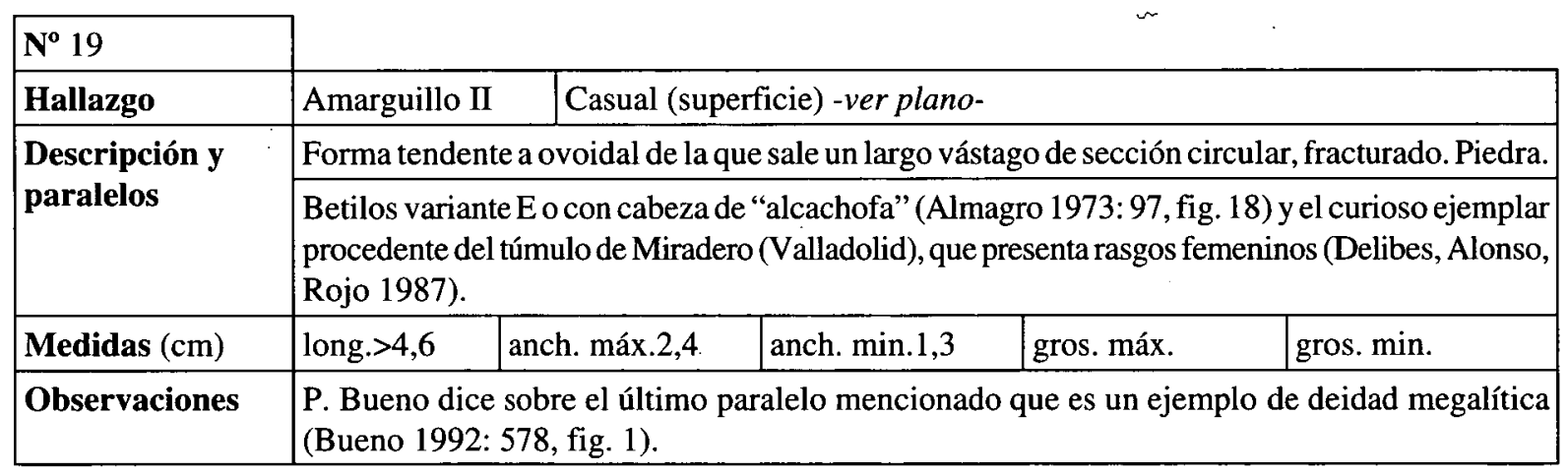

\begin{tabular}{|c|c|c|c|c|c|}
\hline $\mathbf{N}^{\circ} 20$ & & & & & \\
\hline Hallazgo & Amarguillo II & Casual (supe & ficie) & & \\
\hline $\begin{array}{l}\text { Descripción y } \\
\text { paralelos }\end{array}$ & $\begin{array}{l}\text { Tendencia circ } \\
\text { elíptica. Piedra }\end{array}$ & ular; en uno de st & extremos presen & In estrechamiento & ección de tendencia \\
\hline . & $\begin{array}{l}\text { Recuerdan alg } \\
\text { Almería (Alma } \\
\text { considerados cc } \\
\text { (León) (Almag } \\
\text { escocesas, espe } \\
\text { (Powell 1966: } 1 \\
\text { tica", que apares } \\
\text { Morbihan (Fra } \\
\text { (Francia)], y G }\end{array}$ & $\begin{array}{l}\text { o a él, en cuanto } \\
\text { gro 1973, lám. } \\
\text { omo perduracione } \\
\text { ro 1973: } 272 \text { y } 27 \\
\text { ccialmente una d } \\
11 \text {, fig. } 108 \text {, abaj } \\
\text { ce en el pilar graba } \\
\text { ncia)] y en los so } \\
\text { rah- Niol [Arzor }\end{array}$ & $\begin{array}{l}\text { su forma, el denc } \\
\text { XXVIII, 4), los íd } \\
\text { de los ídolos betil } \\
\text {,fig. } 71 \text { ). Tambié } \\
\text { las que aparecen } \\
\text { a la derecha) y la r } \\
\text { de la cámara fune } \\
\text { rtes grabados de } \\
\text { Mobihan, (Franc }\end{array}$ & $\begin{array}{l}\text { inado "ídolo abe } \\
\text { os de Son Maiol } \\
\text { Almagro 1973: } 10 \\
\text { con las salvedades } \\
\text { ografiadas en el } 1 \\
\text { ncionada por Mar } \\
\text { ia del cairn Mané- } \\
\text { Pierres Plates [L } \\
\text { ] (Markale 2000 }\end{array}$ & $\begin{array}{l}\text { nte" de Tabernas en } \\
\text { Iontefí en Mallorca, } \\
\text { y el ídolo de Rodicol } \\
\text { lexpuestas, las bolas } \\
\text { o de T. G. E. Powell } \\
\text { e"Gran Diosa neolí- } \\
\text { Hroeg [Locmariquer, } \\
\text { mariquer, Morbihan } \\
\text { 58-259, 267, 278). }\end{array}$ \\
\hline Medidas $(\mathrm{cm})$ & long. 7,82 & anch. máx.6,78 & anch. $\min .4,32$ & gros. máx.4,44 & gros. $\min .2,66$ \\
\hline
\end{tabular}




\begin{tabular}{|l|l|}
\hline Observaciones & $\begin{array}{l}\text { Además de la conexión, relativa quizá, con las carved stone balls, pensamos que, con más pro- } \\
\text { piedad, esta figura puede asociarse con las representaciones esquemáticas consideradas de la } \\
\text { diosa, que aparecen grabadas en tumbas megalíticas de Bretaña e Irlanda (Gimbutas 1996: 247, } \\
\text { fig. 384, 4 y 6; 291, fig. 458,3). J. Markale interpreta a la diosa neolítica como "ídolo en forma } \\
\text { de marmita" y, en cierta manera, la compara con la representación, según él, extremadamente } \\
\text { simple, de la gran diosa del dolmen de Soto (España) (Markale 2000: 120). Con este producto, }\end{array}$ \\
$\begin{array}{l}\text { asociado por nosotros al grupo de los "ídolos bolas", cerramos el apartado considerado como } \\
\text { tal y cuyo nombre debe, como ya dijimos, a los habitantes del pueblo de Los Molares. }\end{array}$ \\
\hline
\end{tabular}

\begin{tabular}{|c|c|c|c|c|c|}
\hline \multirow{2}{*}{$\begin{array}{l}N^{\circ} 21 \\
\text { Hallazgo } \\
\end{array}$} & \multirow[b]{2}{*}{ Amarguillo II } & \multirow{2}{*}{\multicolumn{3}{|c|}{ Casual (superficie) -ver plano- }} & \\
\hline & & & & & \\
\hline \multirow[t]{2}{*}{$\begin{array}{l}\text { Descripción y } \\
\text { paralelos }\end{array}$} & \multicolumn{5}{|c|}{$\begin{array}{l}\text { Cilíndrico, fracturado en la zona superior, donde parece presentar incisiones agrupadas en dos } \\
\text { grupos de tres. Sección elíptica. Piedra. }\end{array}$} \\
\hline & \multicolumn{5}{|c|}{$\begin{array}{l}\text { Ídolos cilindro, tipo IV, variante B o C de Almagro. En cuanto a la tipología de Bécares se encuadra } \\
\text { en el grupo de ídolos oculados típicos o Io } 1 \text { (Bécares 1983: 143, fig. 2;142, cuadro 2; 1990: } \\
\text { 93, fig. 1-2). }\end{array}$} \\
\hline Medidas $(\mathrm{cm})$ & long. $>7,2$ & anch. máx.4,5 & anch. min. & gros. máx. & gros. min. \\
\hline Observaciones & & & & & \\
\hline
\end{tabular}

\begin{tabular}{|c|c|c|c|c|c|}
\hline $\mathbf{N}^{0} 22$ & & & & & \\
\hline Hallazgo & Amarguillo II & $\begin{array}{l}\text { Prospecció } \\
\text { la excavaci }\end{array}$ & $\begin{array}{l}\text { superficie). En l } \\
\text { arqueológica. }\end{array}$ & imediacione & gar donde se realizó \\
\hline & De tendencia c & cilíndrica, seccio & circular. Fractur & en uno de s & mos. Piedra. \\
\hline Iralelos & $\begin{array}{l}\text { Parece tratarse } \\
\text { aproximadame } \\
\text { liso" establecic } \\
\text { Cerro de San B } \\
\text { Naval de Rota } \\
\text { igualmente, de }\end{array}$ & $\begin{array}{l}\text { de un objeto cor } \\
\text { nte la mitad, no s } \\
\text { do por Almagro } \\
\text { 3enito [Lebrija ( } \\
\text { (Cádiz) (Perdig } \\
\text { un ídolo betilo }\end{array}$ & $\begin{array}{l}\text { lerado tradicion } \\
\text { mos si estaría de } \\
\text { e ser así, tambié } \\
\text { villa)] (Caro Bel } \\
\text { es Moreno et al } \\
\text { po III, variante }\end{array}$ & $\begin{array}{l}\text { ente como íd } \\
\text { ddo o pertene } \\
\text { ndría nume } \\
\text { 1982-83: } 4 \\
985: 80 \text {, fig. } \\
\text { Almagro. }\end{array}$ & $\begin{array}{l}\text { drico. Como le falta } \\
\text { tipo "ídolo cilíndrico } \\
\text { ralelos, como el del } \\
\text { 2, 1B); el de la Base } \\
\text { etc. Podría tratarse, }\end{array}$ \\
\hline Medidas (cm) & long. $>6,5$ & anch. máx.3,2 & anch. $\min .2,8$ & gros. máx. & gros. min. \\
\hline Observaciones & & & & & \\
\hline
\end{tabular}

\begin{tabular}{|c|c|c|c|c|c|}
\hline $\mathbf{N}^{0} 23$ & & & & & \\
\hline Hallazgo ' & Amarguillo II & Casual ( & ficie) & & \\
\hline $\begin{array}{l}\text { Descripción y } \\
\text { paralelos }\end{array}$ & $\begin{array}{l}\text { Tendente a cilí } \\
\text { están inclinado }\end{array}$ & $\begin{array}{l}\text { índrico. Posib } \\
\text { os. Círculo gr }\end{array}$ & $\begin{array}{l}\text { te fracturado } \\
\text { Sección cir }\end{array}$ & $\begin{array}{l}\text { bos extremo } \\
\text { Piedra. }\end{array}$ & en los planos de corte \\
\hline & $\begin{array}{l}\text { Aunque de peor } \\
\text { ídolos cilíndric } \\
\text { megalíticos, ta } \\
\text { fig. 1), y en otra } \\
\text { 1983: 143, fig. }\end{array}$ & $\begin{array}{l}\text { rejecución y m } \\
\text { cos. Motivos } \\
\text { into grabados } \\
\text { as manifestaci } \\
2, \text { grupo bar }\end{array}$ & $\begin{array}{l}\text { prima, podría } \\
\text { lares están } \mathrm{f} \\
\text { pintados }(\mathrm{Bu} \\
\text { de arte esque } \\
\text { puntos, } \mathrm{Bp} 1\end{array}$ & $\begin{array}{l}\text { lizarse con lo } \\
\text { temente repi } \\
\text { 3albín 1992: } \\
\text { (Acosta } 196 \\
\text { 148). }\end{array}$ & $\begin{array}{l}\text { ormente denominados } \\
\text { dos en monumentos } \\
50,66,69,71 ; 1999 \\
115 \text {, fig. } 31 \text {; Bécares }\end{array}$ \\
\hline Medidas $(\mathrm{cm})$ & long.6,5 & anch. máx.4 & anch. min. & gros. máx. & gros. min. \\
\hline Observaciones & & & & & \\
\hline
\end{tabular}




\begin{tabular}{|c|c|c|c|c|c|}
\hline $\mathbf{N}^{\circ} 24$ & & & & & \\
\hline Hallazgo & Amarguillo II & Casual (sup & ficie) & & \\
\hline Descripción y & Tendencia sem & iesférica. Círculo & rabado. Secci & una cara cónce & tra convexa. Piedra. \\
\hline & $\begin{array}{l}\text { Como product } \\
\text { sobre todo la } 2 \\
\text { para que la pie } \\
\text { Respecto al cí } \\
\text { al de la ficha a }\end{array}$ & $\begin{array}{l}\text { os más afines hem } \\
\text { de la fig. } 57 \text {, por } \\
\text { za pueda colgars } \\
\text { rculo que tiene gr } \\
\text { interior, la núm. }\end{array}$ & $\begin{array}{l}\text { considerado } \\
\text { ue está sin de } \\
\text { aunque ésta } \\
\text { jado cerca de }\end{array}$ & $\begin{array}{l}\text { ocidos como l } \\
\text { no presenta } \\
\text { arguillo II es n } \\
\text { sus extremos }\end{array}$ & $\begin{array}{l}\text {, tipo X de Almagro, } \\
\text { aciones susceptibles } \\
\text { más tosca y gruesa. } \\
\text { omentario es similar }\end{array}$ \\
\hline Medidas $(\mathrm{cm})$ & long. 7,2 & anch. máx.11,2 & anch. min. & gros. máx.5 & gros. min. \\
\hline Observaciones & & & & & \\
\hline
\end{tabular}

\begin{tabular}{|c|c|c|c|c|c|}
\hline \multirow{2}{*}{$\frac{\mathbf{N}^{0} 25}{\text { Hallazgo }}$} & \multirow[b]{2}{*}{ Amarguillo II } & \multirow{2}{*}{\multicolumn{3}{|c|}{ Casual (superficie) -ver plano- }} & \\
\hline & & & & & \\
\hline \multirow[t]{2}{*}{$\begin{array}{l}\text { Descripción y } \\
\text { paralelos }\end{array}$} & \multicolumn{5}{|c|}{$\begin{array}{l}\text { Base tendente a circular que se va abriendo hasta formar un extremo biapuntado con una concavidad } \\
\text { en medio. Sección tendente a circular en la base y tendente a rectangular en su extremo opuesto. } \\
\text { Piedra. }\end{array}$} \\
\hline & \multicolumn{5}{|c|}{$\begin{array}{l}\text { Su forma recuerda a la de la losa grabada del recinto del cairn principal de Knowth [Condado } \\
\text { de Meta (Irlanda)] (Markale 2000: } 327 \text { ). También en el mismo condado irlandés, en el guardacantón } \\
\text { número } 52 \text { de la tumba santuario de Newgrange, podemos ver una forma parecida a ésta (Gimbutas } \\
\text { 1996: 238, fig. 370). En la Península Ibérica objetos muebles que podrían ser similares proceden } \\
\text { de yacimientos como Papauvas (Martín de la Cruz 1986: 201, fig. 112, n²050) o Valencina } \\
\text { de la Concepción (Fernández y Oliva 1980: 34, fig. 10, 8.4). }\end{array}$} \\
\hline Medidas $(\mathrm{cm})$ & long. 8,6 & anch. máx.12 & anch. min. & gros. máx.4,1 & gros. min. \\
\hline Observaciones & \multicolumn{5}{|c|}{$\begin{array}{l}\text { En la losa grabada de Knowth hay cuatros motivos a los que J. Markale llama signos, y dice que } \\
\text { en ellos puede verse un símbolo de poder: se trata de cuatro líneas dobles de tendencia semicircular, } \\
\text { con una inversión. de sentido arriba y abajo, acompañadas de un punto central, en las que cree ver } \\
\text { una figuración de dos mundos, el visible y el invisible, uno de los cuales se ve en un espejo } \\
\text { (se pregunta cuál de ellos corresponde a la realidad y qué es entonces la realidad). La de Newgrange } \\
\text { presenta también decoración, en este caso de triángulos, puntos, espirales, etc. }\end{array}$} \\
\hline
\end{tabular}

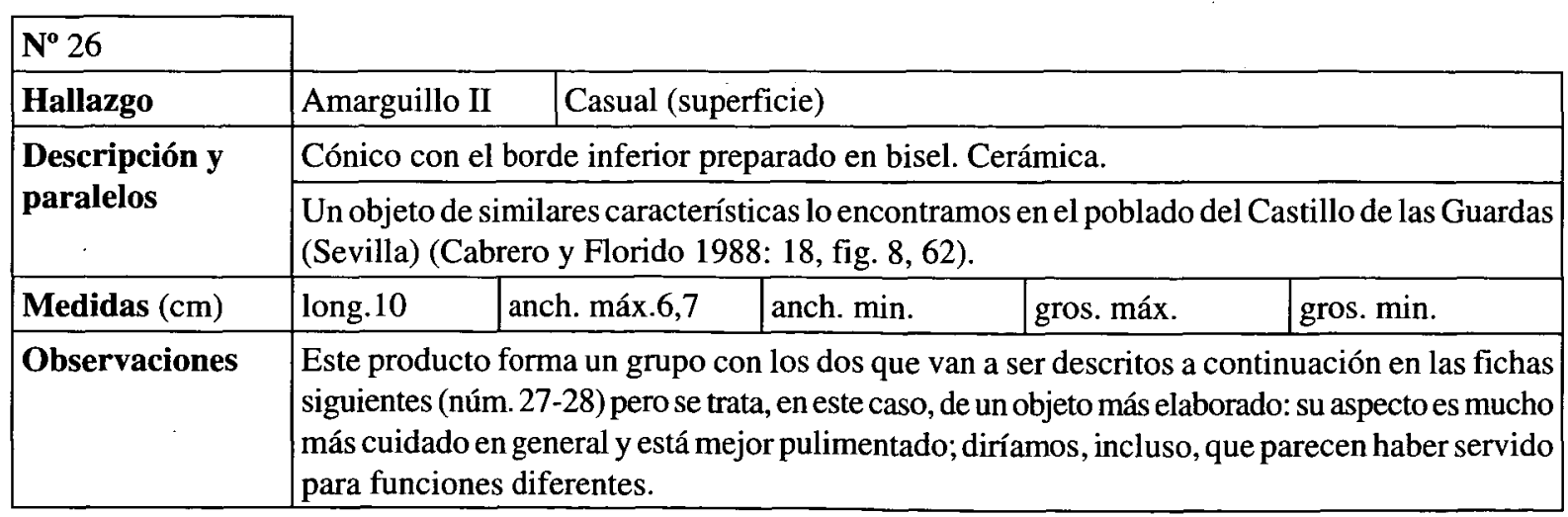




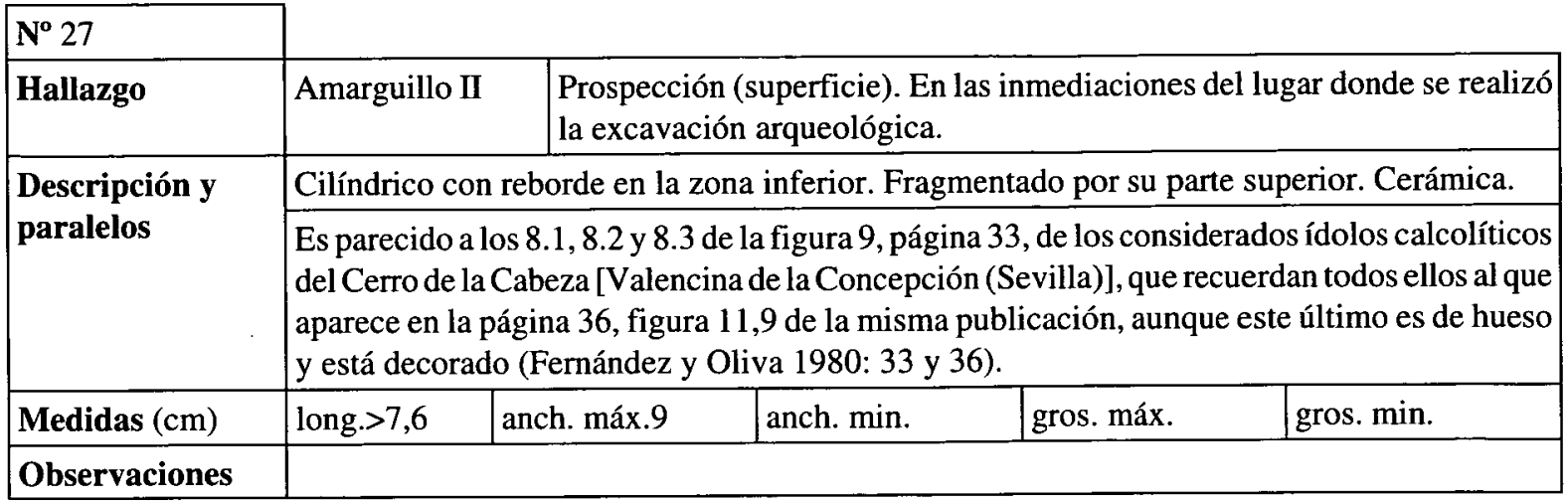

\begin{tabular}{|c|c|c|c|c|c|}
\hline \multirow{2}{*}{$\begin{array}{l}\mathrm{N}^{\circ} 28 \\
\text { Hallazgo }\end{array}$} & \\
\hline & Amarguillo II & \multicolumn{4}{|c|}{$\begin{array}{l}\text { Prospección (superficie). En las inmediaciones del lugar donde se realizó } \\
\text { la excavación arqueológica, pero no estaba próximo al núm. } 27 .\end{array}$} \\
\hline \multirow{2}{*}{$\begin{array}{l}\text { Descripción y } \\
\text { paralelos }\end{array}$} & \multicolumn{5}{|c|}{ Cilíndrico con reborde en la zona inferior. Fragmentado por su parte superior. Cerámica. } \\
\hline & \multicolumn{5}{|l|}{ Ver núm. 27.} \\
\hline Medidas $(\mathrm{cm})$ & long. $>7,8$ & anch. máx.7,9 & anch. min. & gros. máx. & gros. min. \\
\hline Observaciones & & & & & \\
\hline
\end{tabular}

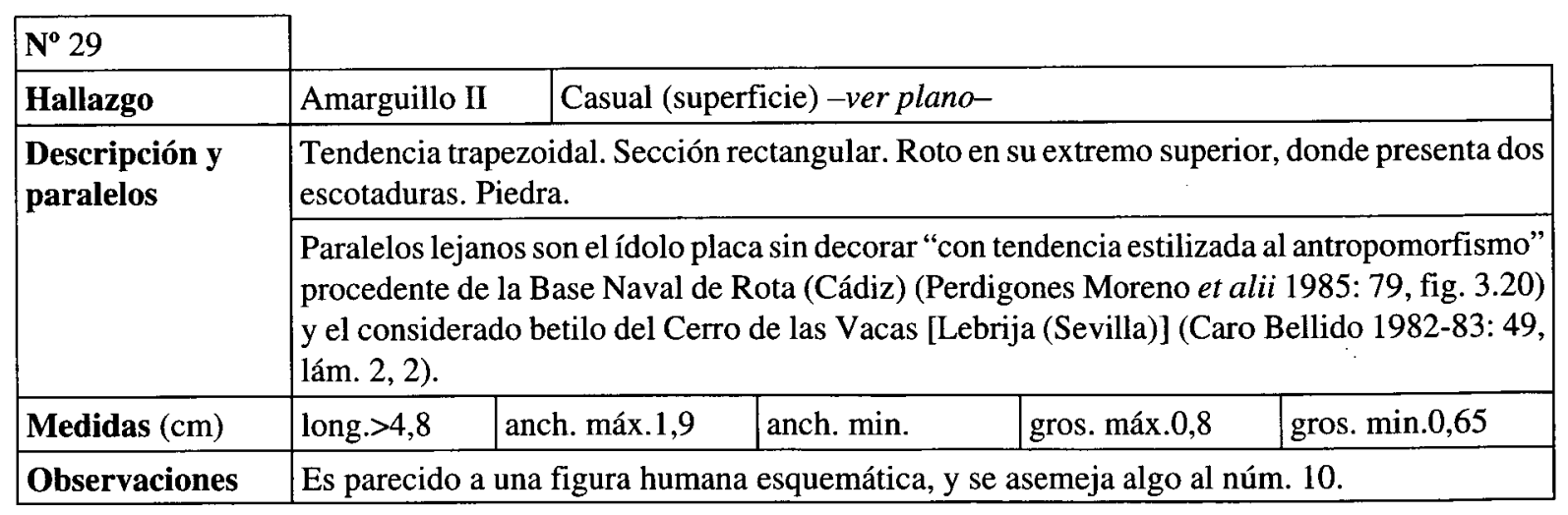




\begin{tabular}{|c|c|c|c|c|c|}
\hline $\mathbf{N}^{\mathbf{0}} 30$ & & & & & \\
\hline Hallazgo & Amarguillo II & Casual (sup & ficie) -ver plan & & \\
\hline & Tendente a trap & pezoidal con los & gulos redondeac & Sección tendente & rectangular. Piedra. \\
\hline & $\begin{array}{l}\text { Considerado tra } \\
\text { forma puede pa } \\
\text { la sección es pla } \\
79, \text { fig. } 3,21 \text { ); pe } \\
\text { ya que el prese } \\
\text { Su silueta es } \\
\text { (Francia)], desc } \\
\text { puede ser un ar } \\
\text { dolménicos estu } \\
\text { también al sopo } \\
\text { el carácter visibl } \\
\text { particularmente } \\
\text { de los triángulo } \\
\text { aludiendo a sus } \\
\text { ídolos placa dec } \\
\text { betilos tanto lis }\end{array}$ & $\begin{array}{l}\text { radicionalmente } \\
\text { aralelizarse con } 1 \\
\text { ana; también con } \\
\text { pero creemos que l } \\
\text { entado por nosotr } \\
\text { s semejante a la } \\
\text { crito como perso } \\
\text { rma o un embler } \\
\text { udiados por Mark } \\
\text { orte grabado de D } \\
\text { lemente decorativ } \\
\text { te los signos serp } \\
\text { os y rombos (Ma } \\
\text { s similitudes, ade } \\
\text { corados (Almagr } \\
\text { sos como decora }\end{array}$ & $\begin{array}{l}\text { mo un ídolo pla } \\
\text { que aparecen e } \\
\text { ro hallado en Ro } \\
\text { diferencia con est } \\
\text { s aquí ofrece un } \\
\text { la estatua menhi } \\
\text { je femenino est } \\
\text { de autoridad y } \\
\text { en Morbihan (F } \\
\text { wth [condado de } \\
\text { de esta imagen no } \\
\text { tiformes que se } \\
\text { ale 2000: } 139 \text { ). } \\
\text { ás de las anterio } \\
\text { 1973: } 215 \text {, fig. } 4 \\
\text { s (Almagro } 197\end{array}$ & $\begin{array}{l}\text { in decorar (Alm } \\
\text { s fichas núm. } 6 \text { a } \\
\text { Cádiz) (Perdigone } \\
\text { timo es significati } \\
\text { ajo mucho más } \\
\text { Rosseironne [Ca } \\
\text { ado que lleva un } \\
\text { forma general re } \\
\text { cia) (Markale } 200 \\
\text { ta (Irlanda)] don } \\
\text { ce olvidar la perm } \\
\text { cuentran en opos } \\
\text { su forma podem } \\
\text { por ejemplo, la d } \\
\text { 216, fig. 50; } 217 \text {, } \\
57 \text {, fig. 8; } 91 \text {, fig. }\end{array}$ & $\begin{array}{l}\text { o } 1973: 200 \text { ) por su } \\
\text { aunque en este caso } \\
\text { Moreno y otros } 1985 \text { : } \\
\text { en cuanto a acabado, } \\
\text { nerado. } \\
\text { Inau-Valence, Gard } \\
\text { gmático objeto, que } \\
\text { erda a los grabados } \\
\text { 98). Algo se asemeja } \\
\text { como dice Markale, } \\
\text { ncia de los símbolos, } \\
\text { ón con la geometría } \\
\text { dar numerosas citas } \\
\text { ana gran cantidad de } \\
\text { 51).y la de muchos } \\
7 \text { arriba). }\end{array}$ \\
\hline Medidas $(\mathrm{cm})$ & 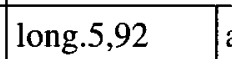 & anch. máx.3,98 & anch. $\min .1,8$ & gros. máx. 0,65 & gros. min. 0,5 \\
\hline
\end{tabular}

\begin{tabular}{|c|c|c|c|c|c|}
\hline \multirow{2}{*}{$\frac{\mathbf{N}^{\mathbf{0}} 31}{\text { Hallazgo }}$} & \multirow[b]{2}{*}{ Amarguillo II } & \multirow{2}{*}{\multicolumn{2}{|c|}{ Casual (superficie) }} & & \\
\hline & & & & & \\
\hline \multirow[t]{2}{*}{$\begin{array}{l}\text { Descripción y } \\
\text { paralelos }\end{array}$} & \multicolumn{5}{|c|}{$\begin{array}{l}\text { Tendente a rectangular. Sección tendente a rectangular pero cortada de forma biselada en uno } \\
\text { de sus lados largos. Piedra. }\end{array}$} \\
\hline & \multicolumn{5}{|c|}{$\begin{array}{l}\text { Guarda cierta similitud con algunos de los denominados ídolos placa tipos VIII A, VIII B y } \\
\text { VIII C de Almagro (Almagro 1973: 200-201, fig. 34-35). }\end{array}$} \\
\hline Medidas $(\mathrm{cm})$ & long.5,8 & anch. máx.2,3 & anch. min. & gros. máx. 0,6 & gros. $\min .0,3$ \\
\hline Observaciones & & & & & \\
\hline
\end{tabular}

\begin{tabular}{|c|c|c|c|c|c|}
\hline \multirow{2}{*}{\begin{tabular}{|l}
$N^{\circ} 32$ \\
Hallazgo
\end{tabular}} & \multirow{2}{*}{ Amarguillo II } & \multirow{2}{*}{\multicolumn{2}{|c|}{ Casual (superficie) }} & & \\
\hline & & & & & \\
\hline \multirow[t]{2}{*}{$\begin{array}{l}\text { Descripción y } \\
\text { paralelos }\end{array}$} & \multicolumn{5}{|c|}{$\begin{array}{l}\text { Tendente a rectangular. La mitad de la superficie de uno de sus lados está deteriorada. Sección } \\
\text { tendente a rectangular. Piedra. }\end{array}$} \\
\hline & \multicolumn{5}{|l|}{ Ver núm. 31.} \\
\hline Medidas $(\mathrm{cm})$ & long.7,5 & anch. máx.3,1 & anch. $\min .2,5$ & gros. máx. 0,8 & gros. min. \\
\hline Observaciones & & & & & \\
\hline
\end{tabular}




\begin{tabular}{|c|c|c|c|c|c|}
\hline \multirow{2}{*}{$\frac{\mathbf{N}^{0} 33}{\text { Hallazgo }}$} & \multicolumn{5}{|c|}{ · } \\
\hline & Amarguillo II & \multicolumn{4}{|c|}{ Casual (superficie) } \\
\hline \multirow[t]{2}{*}{$\begin{array}{l}\text { Descripción y } \\
\text { paralelos }\end{array}$} & \multicolumn{5}{|c|}{$\begin{array}{l}\text { Tendente a rectangular. Fragmentada (falta más de la mitad de la pieza). Sección tendente a } \\
\text { rectangular. Piedra. }\end{array}$} \\
\hline & \multicolumn{5}{|l|}{ Ver núm. 31.} \\
\hline Medidas (cm) & long. $>5,4$ & anch. máx.4,7 & anch. min. & gros. máx.0,6 & gros. min. \\
\hline Observaciones & & & & & \\
\hline
\end{tabular}

\begin{tabular}{|c|c|c|c|c|c|}
\hline \multirow{2}{*}{\begin{tabular}{|l|}
$N^{\circ} 34$ \\
Hallazgo
\end{tabular}} & & & & & \\
\hline & Amarguillo II & \multicolumn{4}{|c|}{ Casual (superficie) } \\
\hline \multirow[t]{2}{*}{$\begin{array}{l}\text { Descripción y } \\
\text { paralelos }\end{array}$} & \multicolumn{5}{|c|}{$\begin{array}{l}\text { Tendente a rectangular. Fragmentada (falta aproximadamente la mitad de la pieza). Secciór } \\
\text { tendente a rectangular. Piedra. }\end{array}$} \\
\hline & \multicolumn{5}{|l|}{ Ver núm. 31.} \\
\hline Medidas $(\mathrm{cm})$ & long.>4 & anch. máx.2,8 & anch. min. & gros. máx.0,6 & gros. min. \\
\hline Observaciones & & & & & \\
\hline
\end{tabular}

\begin{tabular}{|c|c|c|c|c|c|}
\hline $\mathbf{N}^{\circ} 35$ & \\
\hline Hallazgo & Amarguillo II & \multicolumn{4}{|c|}{ Casual (superficie) } \\
\hline \multirow[t]{2}{*}{$\begin{array}{l}\text { Descripción y } \\
\text { paralelos }\end{array}$} & \multicolumn{5}{|c|}{$\begin{array}{l}\text { Forma tendente a rectangular con la zona superior redondeada. Muy deteriorado y fragmentado. } \\
\text { Sección de tendencia rectangular. Presenta una perforación en su extremo superior. Piedra. }\end{array}$} \\
\hline & \multicolumn{5}{|l|}{ Ver núm. 31.} \\
\hline Medidas (cm) & long. $>4,8$ & anch. máx.3,2 & anch. min. & gros. máx.0,6 & gros. min. \\
\hline Observaciones & & & & & \\
\hline
\end{tabular}

\begin{tabular}{|c|c|c|c|c|c|}
\hline \multirow{2}{*}{$\frac{N^{0} 36}{\text { Hallazgo }}$} & & & & & \\
\hline & Amarguillo II & \multicolumn{4}{|c|}{ Casual (superficie) } \\
\hline \multirow[t]{2}{*}{$\begin{array}{l}\text { Descripción y } \\
\text { paralelos }\end{array}$} & \multicolumn{5}{|c|}{$\begin{array}{l}\text { Fragmento decorado con líneas grabadas que se entrecruzan, formando un motivo en damero } \\
\text { Sección de tendencia rectangular. Piedra. }\end{array}$} \\
\hline & \multicolumn{5}{|c|}{$\begin{array}{l}\text { Podría tratarse de un fragmento de un ídolo placa decorado, muy numerosos en la bibliografía } \\
\text { (Almagro 1973: 181-223, fig. 36-51). }\end{array}$} \\
\hline Medidas (cm) & long. & anch. máx. & anch. $\min$. & gros. máx.0,6 & gros. min. \\
\hline Observaciones & & & & & \\
\hline
\end{tabular}

\begin{tabular}{|c|c|c|c|c|c|}
\hline \multirow{2}{*}{$\begin{array}{l}\mathbf{N}^{\mathbf{0}} 37 \\
\text { Hallazgo }\end{array}$} & & & & & \\
\hline & Amarguillo II & \multicolumn{4}{|c|}{ Casual (superficie) } \\
\hline $\begin{array}{l}\text { Descripción y } \\
\text { paralelos }\end{array}$ & \multicolumn{5}{|c|}{$\begin{array}{l}\text { Parte central cónica y dos vástagos que se unen a ella por dos acanaladuras que rodean el } \\
\text { contorno. Piedra. }\end{array}$} \\
\hline Medidas $(\mathrm{cm})$ & long.>4 & anch. máx.1,7 & anch. $\min$. & gros. máx. & gros. $\min$. \\
\hline
\end{tabular}




\begin{tabular}{|l|l|}
\hline Observaciones & $\begin{array}{l}\text { Recuerda ligeramente al producto procedente de Blanquizares de Lebor (Murcia) (Almagro } \\
1973: 121, \text { fig. 20, 29), pero la sección es diferente. No obstante, se trata de un ejemplar fragmentado } \\
\text { el que presentamos y de forma no muy frecuente, por ello más difícil de encontrar afinidades } \\
\text { con otros productos. }\end{array}$ \\
\hline
\end{tabular}

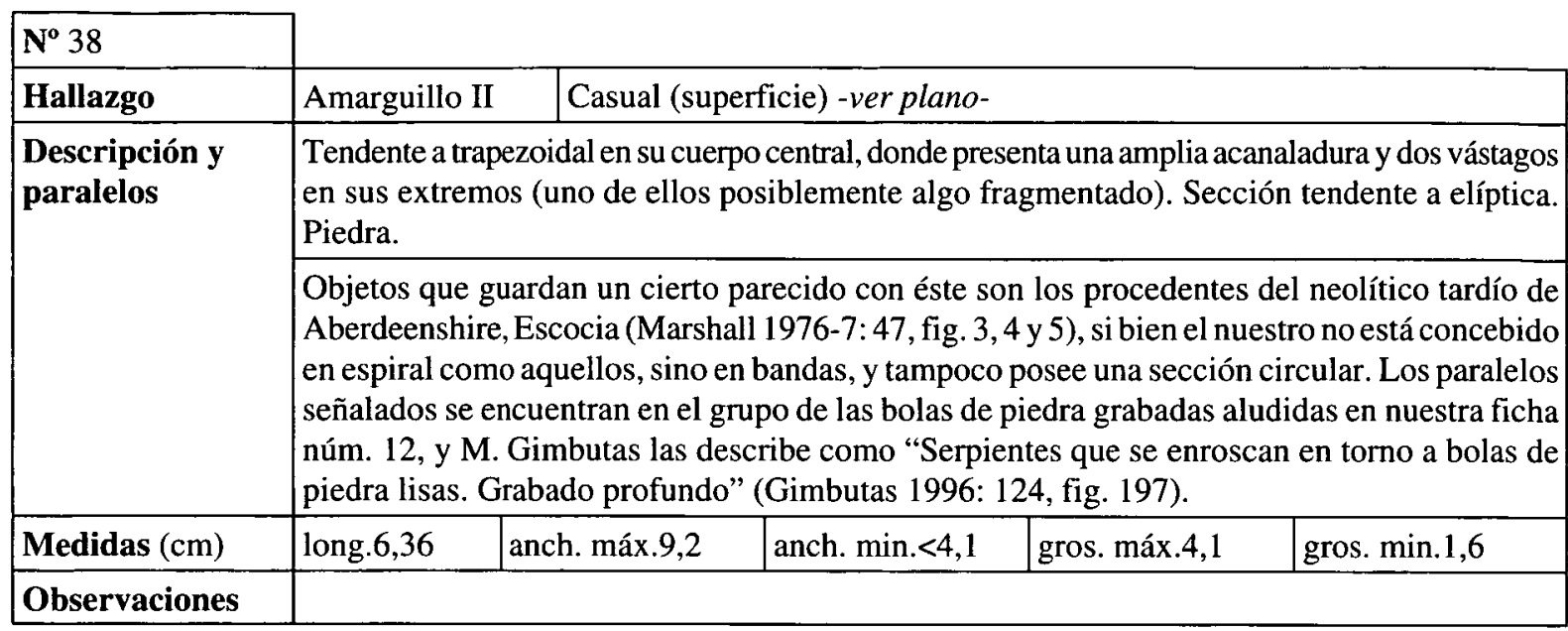

\begin{tabular}{|c|c|c|c|c|c|}
\hline $\mathbf{N}^{\circ} 39$ & & & & & \\
\hline Hallazgo & Amarguillo II & Casual (sup & ficie) -ver plano- & & \\
\hline Descripción y & Escultura natu & ralista represent & do un falo. Piedr & & \\
\hline paralelos & $\begin{array}{l}\text { Betilos portug } \\
\text { fálicos encont } \\
\text { fálicas son frec } \\
\text { y Balbín } 1996\end{array}$ & $\begin{array}{l}\text { ueses sin decorar } \\
\text { rados en la cueva } \\
\text { uentes en menhire } \\
\text {; Calado y otros }\end{array}$ & $\begin{array}{l}\text { de forma fálica ( } \\
\text { le la Marsella (Al } \\
\text { Bueno y Gonzále } \\
\text { 03). }\end{array}$ & $\begin{array}{l}\text { lagro 1973: 77, } \\
\text { gro 1973: 121, } \\
\text { ordero 1995; Go }\end{array}$ & $\begin{array}{l}\text { 12) Colgantes betilo } \\
\text { 20, 19-26). Formas } \\
\text { Varela 1994; Bueno }\end{array}$ \\
\hline Medidas $(\mathrm{cm})$ & long.11,2 & anch. máx.4,65 & anch. $\min .2,65$ & gros. máx. 4,7 & gros. min. \\
\hline Observaciones & & & & & \\
\hline
\end{tabular}

\begin{tabular}{|c|c|c|c|c|c|}
\hline \multirow{2}{*}{$\begin{array}{l}\mathrm{N}^{\circ} 40 \\
\text { Hallazgo }\end{array}$} & \multirow{2}{*}{ Amarguillo II } & \multirow{2}{*}{\multicolumn{2}{|c|}{ Casual (superficie) }} & & \\
\hline & & & & & \\
\hline \multirow[t]{2}{*}{$\begin{array}{l}\text { Descripción y } \\
\text { paralelos }\end{array}$} & \multicolumn{5}{|c|}{$\begin{array}{l}\text { Triangular. Tiene dos partes grabadas opuestas en una de sus caras, a modo de ojos. Sección } \\
\text { rectangular. Piedra. }\end{array}$} \\
\hline & \multicolumn{5}{|c|}{$\begin{array}{l}\text { Pequeñas piezas triangulares y tendentes a triangulares han sido detectadas en megalitos gallegos, } \\
\text { portugueses y andaluces. El aspecto triangular de algunas es comparable a la del dolmen I de } \\
\text { Lameira da Cima (Viseu, Portugal), fechado por }{ }^{14} \mathrm{C} \text {, sin calibrar, en el IV milenio (Bueno y } \\
\text { Balbín 2000: 59, fig. 4). }\end{array}$} \\
\hline Medidas $(\mathrm{cm})$ & long.3 & anch. máx. 4,2 & anch. min. & gros. máx.1,8 & gros. min. \\
\hline
\end{tabular}




\begin{tabular}{|l|l|}
\hline Observaciones & $\begin{array}{c}\text { Objetos como este son frecuentes en el yacimiento de Amarguillo II y varía solamente el tamaño } \\
\text { de los mismos; todos son de piedra excepto el que aparece en la ficha siguiente, la núm. 41, que } \\
\text { es de concha. E. Shee indica que entre los principales motivos del arte megalítico están las filas } \\
\text { de triángulos y los motivos dentados, muy frecuentes en Bretaña e Irlanda (Shee 1981: 107, 10). } \\
\text { La figurilla femenina trilobulada de Campu-Fiurelli citada en la ficha núm. 11, lleva dos } \\
\text { triángulos incisos: uno en el pecho y otro en el pubis. } \\
\text { En pintura esquemática son numerosos los motivos triangulares por todo el territorio peninsular, } \\
\text { considerados representaciones antropomorfas (Acosta 1968: 74,75, 77, 80, 147, 158 160, 167; } \\
\text { Ramos y Giles 1966: 291, capítulo 11), y generalmente no aparecen aislados. Son numerosos } \\
\text { losídolos placa que están decorados con filas de triángulos, normalmente rellenos con retícula } \\
\text { (Gimbutas 1996, fig. 371; Almagro 1973: 181-216). } \\
\text { Un triángulo constituye la base del denominado ídolo de San Bartolomé de la Torre (Huelva) } \\
\text { (Almagro 1973, lám. XL, 1)en cuya cara anterior se considera que está grabada una representación } \\
\text { del árbol de la vida (“del triangulo sale la vida"); el resto del mismo está también decorado } \\
\text { con triángulos rellenos de puntos, tema éste ampliamente representado por las tierras cercanas } \\
\text { al Mediterráneo, decorando fundamentalmente recipientes cerámicos y figurillas femeninas. } \\
\text { El triángulo es el símbolo de la vulva (triángulo púbico) y de la Diosa ode su poder regenerador, } \\
\text { remontándose sus orígenes a momentos muy antiguos (Gimbutas 1996: 237). }\end{array}$ \\
\hline
\end{tabular}

\begin{tabular}{|c|c|c|c|c|c|}
\hline \multirow{2}{*}{\begin{tabular}{|l}
$N^{\circ} 41$ \\
Hallazgo
\end{tabular}} & & \multirow{2}{*}{\multicolumn{4}{|c|}{ Casual (superficie) -ver plano- }} \\
\hline & Amarguillo II & & & & \\
\hline $\begin{array}{l}\text { Descripción y } \\
\text { paralelos }\end{array}$ & \multicolumn{5}{|c|}{ Triángulo. Concha pulida. } \\
\hline Medidas $(\mathrm{cm})$ & long. 3,7 & anch. máx.4,4 & anch. min. & gros. máx.0,7 & gros. min. \\
\hline Observaciones & \multicolumn{5}{|l|}{ Ver núm. 40.} \\
\hline
\end{tabular}

\begin{tabular}{|c|c|c|c|c|c|}
\hline $\mathbf{N}^{\circ} 42$ & & & & & \\
\hline Hallazgo & Amarguillo II & Casual ( & ficie) -ver plc & & \\
\hline $\begin{array}{l}\text { Descripción y } \\
\text { paralelos }\end{array}$ & $\begin{array}{l}\text { Circular. Secci } \\
\text { y en ellas apar }\end{array}$ & $\begin{array}{l}\text { on tendente a } \\
\text { cen motivos }\end{array}$ & $\begin{array}{l}\text { (convexa). } \mathrm{P} \\
\text { los y grabado }\end{array}$ & $\begin{array}{l}\text { ulida sólo en las } \\
\text { opomorfos esqu }\end{array}$ & $\begin{array}{l}\text { uperficies convexas, } \\
\text { iticos, punto, trazos. }\end{array}$ \\
\hline & (Bueno y Ball & ín 1996). & & & \\
\hline Medidas $(\mathrm{cm})$ & long.9,8 & anch. máx. & anch. min. & gros. máx.2,8 & gros. min. \\
\hline Observaciones & $\begin{array}{l}\text { En este último } \\
\text { con pinturas e } \\
\text { monumentos 1 } \\
\text { aquí dada la fa } \\
\text { de Amarguillo } \\
\text { materias prim } \\
\text { sido trabajada } \\
\text { han pintado s } \\
\text { Las pintur } \\
\text { de distintos tip } \\
\text { y que ya hemo } \\
\text { aquí una pequ } \\
\text { estos dibujosp } \\
\text { que se escapa }\end{array}$ & $\begin{array}{l}\text { partado, quer } \\
\text { quemáticas, } \\
\text { legalíticos oe } \\
\text { ta de espacio } \\
\text { II e igualmen } \\
\text { s, a veces tra } \\
\text { y convertid } \\
\text { bre ellas. } \\
\text { s son rojas y } \\
\text { os, puntos, se } \\
\text { iniciado de ma } \\
\text { eña muestra c } \\
\text { eden ser post } \\
\text { "a simple v }\end{array}$ & $\begin{array}{l}\text { nencionar lae } \\
\text { s con pintura } \\
\text { vas y abrigos } \\
\text { disponemos } \\
\text { an recogido e } \\
\text { lugares muy } \\
\text { atensilios (ha } \\
\text { s, y los motiv } \\
\text { formes, etc., } \\
\text { terdisciplinar } \\
\text { s, pero en nir } \\
\text { ente modifica } \\
\text { usando sólc }\end{array}$ & $\begin{array}{l}\text { cia de un buen núm } \\
\text { abados, semejant } \\
\text { les, cuyo estudio } \\
\text { eden todas del mi } \\
\text { erficie. Se trata de } \\
\text { dos del yacimient } \\
\text { percutores, etc.) } \\
\text { y diversos: antro } \\
\text { uieren un detallac } \\
\text { iversos centros de } \\
\text { aso se trata de ca } \\
\text { I menos en adicion } \\
\text { jequeña lupa ma }\end{array}$ & $\begin{array}{l}\text { de piedras decoradas } \\
\text { los que aparecen en } \\
\text { ia imposible abordar } \\
\text { poblado calcolítico } \\
\text { dras de muy diversas } \\
\text { ue en unos casos han } \\
\text { otros simplemente } \\
\text { torfos esquemáticos } \\
\text { studio de laboratorio } \\
\text { stigación. Ofrecemos } \\
\text { exactos, por lo que } \\
\text { le numerosos detalles } \\
\text { l. }\end{array}$ \\
\hline
\end{tabular}




\section{CONSIDERACIONES FINALES}

De nuevo volvemos a recordar lo ya expuesto al principio de este texto en lo referente a la procedencia de los objetos aquí agrupados, lo cual incide en la provisionalidad de las conclusiones que vamos a exponer.

Al respecto, reiteramos que ya se ha abierto el camino de las analíticas a realizar en cada uno de ellos, lo que ayudará a esclarecer algunas de las preguntas que nos hacemos sobre los mismos y que sin duda, tanto en la teoría como en la praxis, tendrá repercusiones que se expondrán en futuros trabajos.

Hacemos ahora una reflexión que creemos conveniente resaltar y que está en relación con el Patrimonio Histórico, concretamente con el Patrimonio Arqueológico, recordando que no es infinito ni renovable; cuando se termine (la destrucción es constante) nadie podrá paliar su pérdida y las generaciones futuras, sin duda, pedirán cuenta de ello.

Aunque se tratase en todos los casos de productos (Ruiz et alii 1986) generados por la sociedad que vivió en el yacimiento de Amarguillo II en el III milenio a.n.e., a cuyo posible esclarecimiento ayudarán las analíticas pertinentes, formarían parte de una cadena operativa económico-social cuya investigación se podrá seguir sólo de manera incompleta, pues parte de los eslabones se han perdido.

Creemos que la mayoría de estos objetos podrían estar relacionados con el denominado Arte Esquemático Típico. Sabemos que éste aparece en paredes y techos de monumentos megalíticos, en cuevas y abrigos naturales, en rocas al aire libre y en objetos muebles; siendo precisamente a este último grupo donde podrían adscribirse los antes mencionados.

En algunas de las piezas dadas a conocer en este trabajo se advierten motivos pintados/grabados: en unos casos sirven de soporte artefactos pulimentados como hachas, percutores, etc., y en otros, piedras preparadas previamente, o sin preparar (cantos rodados). Los restantes objetos que recogemos, de uso indefinido, presentan formas coincidentes con otras que aparecen en la Península Ibérica, pintadas o grabadas en paredes, techos, etc. de recintos naturales o contenedores artificiales; así como con otras que vemos en productos muebles que se han localizado en diversos yacimientos de cronología afín. Y si a ello se añade que sus paralelos han sido hallados también en otros lugares de la fachada atlántica europea, como Bretaña, Escocia e Irlanda, y de la zona mediterránea, como Malta, todos ellos con fechas y contextos similares, su interés e importancia aumenta

Somos conscientes que para conocer a una sociedad prehistórica, es necesario saber su modo de producción (investigando la fuerza de trabajo, los medios de producción, la propiedad y las relaciones sociales), que genera una conciencia social (reflejo cognitivo -en este caso no sólo la conciencia habitual sino también reflexiva- y afectivo) y un modo de vida (Sarmiento 1992); todo lo cual es esencial para hilar la historia de unas sociedades que vivieron en la campiña sevillana en unos momentos cruciales: cuando la complejidad alcanzada fue tal que el Estado hizo su aparición con un centro organizador geopolítico de la magnitud del poblado de Valencina de la Concepción, del que parece fue Amarguillo II asentamiento de intermediación tributaria (López y Pajuelo 2001:207-227; Pajuelo y López 2001: 229-255).

De las interpretaciones que se han hecho sobre este Arte Esquemático, queremos recordar tres. P. Acosta insistió en la relación de lo pintado y los lugares donde están ubicados, afirmando que no todos tienen que adquirir un sentido eminentemente religioso; por el contrario, muchos de los paneles podrían materializar una "escritura ideográfica" que reflejaría las características de la sociedad que los creó, sus actividades cotidianas, sus estructuras y un importante componente de culto a los antepasados. J. L. Sanchidrián indica que es lícito suponer que una misma expresión gráfica tendría diversificadas funciones en virtud del contexto en donde ésta se encuentre (Sanchidrián 2001: 474-484). Por su parte, P. Bueno y R. de Balbín consideran que el arte megalítico responde a un código funerario que forma parte de un sistema de expresión de mayor amplitud y funcionalidades diversas que es el Arte Esquemático que se inicia en el Neolítico, y que la sociedad 
objeto de estudio es compleja, con muchas expresiones gráficas en las que el hombre es un actor, ya no un espectador, destacando la gran cantidad de representaciones antropomorfas en este arte frente al predominio del tema animalístico en el arte paleolítico.

\section{BIBLIOGRAFÍA}

Hemos seguido fundamentalmente dos tipologías:

ALMAGRO GORBEA, M. J. (1973): Los ídolos del Bronce I Hispano, Biblioteca Praehistorica Hispana, Vol. XII, Madrid.

BÉCARES PÉREZ, J. (1983): «Hacia nuevas técnicas de trabajo en el estudio de la pintura rupestre esquemática», Zephyrus XXXVI: 137-148.

Siempre que hagamos alusión a estos autores sin citar bibliografía nos referimos a estas dos obras.

ACOSTA MARTÍNEZ, P. (1968): La pintura rupestre esquemática en España, Salamanca.

ALMAGRO GORBEA, M. J. (1969): «Los "ídolos cilindros" del Bronce I en la Península Ibérica», Trabajos de Prehistoria 26: 221-274.

(1973): Los ídolos del Bronce I Hispano, Biblioteca Praehistorica Hispana, Vol. XII, Madrid.

ÁLVAREZ ROJAS, A. (1982): «Ídolo cilindro del Cerro de Las Vacas (Trebujena, Cádiz)», Zephyrus XXXIV-XXXV: 119-121.

BALBÍN BEHRMANN, R.; BUENO RAMÍREZ, P. (1996): «Soto, un ejemplo de arte megalítico al suroeste de la península», "El hombre fósil" 80 años después, Santander: 467-505.

BÉCARES PÉREZ, J. (1983): «Hacia nuevas técnicas de trabajo en el estudio de la pintura rupestre esquemática», Zephyrus XXXVI: 137-148.

- (1990): «Uniformidad conceptual en los ídolos del calcolítico peninsular», Zephyrus XLIII: 87-94.

BLASCO RODRÍGUEZ, F. y ORTIZ ALESON, M. (1991): «Trabajos arqueológicos en "Huerta Montero". Almendralejo, Badajoz», I Jornadas de Prehistoria y Arqueología en Extremadura (1986-1990), Extremadura Arqueológica II: 129-137.

BUENO RAMÍREZ, P. (1992): «Les plaques décorées aléntejaines: approche de leur étude et analyse», L'Anthropologie, Tome 96, $\mathrm{n}^{\circ}$ 2-3 : 573-604.

BUENO RAMÍREZ, P. y GONZÁLEZ CORDERO, A. (1995): «Nuevos datos para la contextualización arqueológica de estatuas menhir y estelas antropomorfas en Extremadura», Trabalhos de Antropología e Etnología 35: 95-106. VII Est. Porto.

BUENO RAMÍREZ, P. y BALBÍN BEHRMANN, R. de (1992): «L'Art Mégalithique dans la Péninsule Ibérique: une vue d'ensemble», L'Anthropologie 96, n² 2-3: 499-572.

(1996): «El papel del elemento antropomorfo en el arte megalítico ibérico», Rev. Archéol. Ouest. Supplément $n^{\circ}$ 8: 41-64.

- (2000): «Tècniques, extensió geogràfica i cronologia de l'Art megalític ibèric. El cas de Catalunya», Cota Zero 16: 47-64.

— (2002): «L'Art mégalithique péninsulaire et l'Art mégalithique de la façade atlantique: un modèle de capillarité appliqué à l'Art post-paléolithique européen", L'Anthropologie 106: 603-646.

CABRERO GARCÍA, R. (1986): «Informe preliminar sobre las excavaciones arqueológicas realizadas en el yacimiento de Amarguillo II (Los Molares, Sevilla)», Anuario Arqueológico de Andalucía II: 180-185.

(1987): «El poblado de la Edad del Cobre denominado Amarguillo II (Los Molares, Sevilla). Informe preliminar tras la excavación sistemática de 1987», Anuario Arqueológico de Andalucía II: 276-277.

- (1988): El fenómeno megalítico en Andalucía Occidental, IV Tomos, Microfichas, Sevilla. 
CABRERO GARCÍA, R. y FLORIDO NAVARRO, C. (1988): «Un importante enclave arqueologico de la Edad del Bronce situado en el término municipal del Castillo de las Guardas (Sevilla): tumbas megalíticas y poblado» I Congreso Nacional Cuenca Minera de Riotinto: 1-18.

CABRERO GARCÍA, R.; RUÍZ MORENO, M. T.; CUADRADO MARTÍN, L. B.; SABATÉ DÍAZ, I.; MALGOSA MORERA, A.; VALVERDE LASANTA, M.; SAFONT MAS, S.; GONZÁLEZ RODRÍGUEZ, M.; SUBIRÁ DE GALDÁCANO, M. E.; GONZÁLEZ VILCHES, M. C.; PASCUAL MARTÍNEZ, E. y BARDERA SOLER DE MORELL, R. (1993): «El poblado metalúrgico de Amarguillo II en los Molares (Sevilla) y su entorno inmediato en la campiña: últimas analíticas realizadas», Anuario Arqueológico de Andalucía II: 131-141.

CABRERO GARCÍA, R.; RUIZ MORENO, M.T.; SABATÉ DÍAZ, I. y CUADRADO MARTÍN, L.B. (1996): «Artefactos de tradición neolítica en sociedades prehistóricas de la provincia de Sevilla: Cronología y cambio cultural», I Congrés del Neolitic a la Península Ibérica, Gavá-Bellaterra (Barcelona, 1995). Rubrigatum I, Vol. 1: 191-200.

CALADO, D.; NOCETE, F.; CÁMALICH, M. D.; MARTÍN, D.; NIETO, J. M.; ALEX, E. y BAYONA, M. (2003): «Los poblados con menhires del Algarve Occidental: nuevas perspectivas para la explicación del origen e implicaciones históricas sobre las primeras sociedades sedentarias en el suroeste peninsular», Resúmenes de las Jornadas Temáticas Andaluzas de Arqueología: sociedades recolectoras y primeros productores, Ronda: resumen núm. 11.

CARO BELLIDO, A. (1982-83): «Ídolos del Calcolítico de la zona de Lebrija (Sevilla)», Mainake IV-V: 39-52.

DELIBES, G.; ALONSO, M. y ROJO, M. (1987): «Los sepulcros colectivos del Duero medio y de las Loras y su conexión con el foco dolménico riojano», El megalitismo en la Península Ibérica: 181-197, Ministerio de Cultura, Madrid.

FERNÁNDEZ, F. y OLIVA, D. (1980): «Los ídolos calcolíticos del Cerro de la Cabeza (Valencina de la Concepción, Sevilla)», Madrider Mitteilungen 21: 20-44.

GIMBUTAS, M. (1996): El lenguaje de la diosa, Oviedo.

GOMES VARELA, M. (1994): «Menires e cromleques no complexo cultural megalítico portugués. Trabalhos recentes e estado da questao», Actas do Seminario O Megalitismo no Centro de Portugal: 317-342. Viseu.

GUILAINE, J. (1976): Premiers bergers et paysans de l'Occident méditerranèen, París.

HEDGES, R. E. M.; HOUSLEY, R. A.; BRONK RAMSEY, C. and VAN KLINKEN, G. J. (1995): «Radiocarbon dates from the Oxford ams System: Archaeometry Datelist 19», Archaeometry 37(1): 195-214.

LÓPEZ ALDANA, P. M. y PAJUELO PANDO, A. (2001): «Estrategias político-territoriales de un poder central: el Bajo Guadalquivir en el III milenio a.n.e.», RAMPAS 4: 207-227.

MARKALE, J. (2000): A civilizacion megalítica. Dolmens e menhires, A Coruña.

MARSHALL, D. N. (1976-7): «Carved stone balls», Proceedings of the Society of Antiquaries of Scotland 108: 40-72.

MARTÍN DE LA CRUZ, J. C. (1986): Papauvas II (Aljaraque, Huelva). Campañas de 1981 a 1983, Excavaciones arqueológicas en España 149. Madrid.

NIETO, J. M.; NOCETE, F.; SÁEZ, R. y FRANCO, F. (2002): «Cambios mineralógicos en restos óseos en función de las condiciones de $\mathrm{pH}$ del suelo», Geogaceta 31: 189-192.

NOCETE, F. (2001): Tercer milenio antes de nuestra era: relaciones y contradicciones centro/periferia en el Valle del Guadalquivir, Barcelona.

PAJUELO PANDO, A. y LÓPEZ ALDANA, P. M. (2001): «Ideología y control político durante el III milenio a.n.e. en el Bajo Guadalquivir», RAMPAS 4: 229-255. 
OBJETOS DIVERSOS PROCEDENTES DEL POBLADO CALCOLÍTICO DE AMARGUILLO II (LOS MOLARES, SEVILLA) 167

PECERO ESPÍN, J. C. y GUIJO MAURI, J. M. (1998): «Evidencias Osteológicas de la Necrópolis de La Traviesa: Caracterización Antropológica y Tafonómica», La Traviesa. Ritual Funerarioy Jerarquización Social en una Comunidad de la Edad del Bronce de Sierra Morena Occidental, L. García Sanjuán (Editor), Spal Monografías I: 191-216.

PERDIGONES MORENO, C.; MUÑOZ VICENTE, A.; BLANCO JIMÉNEZ, F.J. y RUÍZ FERNÁNDEZ, J. A. (1985): «Excavaciones de urgencia en la Base Naval de Rota (Puerto de Santa María, Cádiz)», Anuario Arqueológico de Andalucía III: 74-81.

POWELL, T. G. E. (1966): Prehistoric Art, London.

RAMOS MUÑOZ, J. y GILES PACHECO, F. (1996): El Dolmen de Alberite (Villamartín). Aportaciones a las formas económicas y sociales de las comunidades neolíticas en el noroeste de Cádiz, Universidad de Cádiz y Ayuntamiento de Villamartín.

ROMERO BOMBA. E. (1997): «La intervención arqueológica en la estructura megalítica de Valdelinares (Zufre, Huelva)», Anuario Arqueológico de Andalucía III: 376-383.

RUIZ DELGADO, M. M. (1985): Carta Arqueológica de la campiña sevillana. Zona Sureste I, Publicaciones de la Universidad de Sevilla, número 80.

RUIZ RODRÍGUEZ, A.; MOLINOS MOLINOS, M.; NOCETECALVO, F. y CASTROLÓPEZ, M. (1986): «Concepto de producto en arqueología», Coloquio sobre el microespacio-1, Arqueología Espacial 7: 63-80. Teruel.

SANCHIDRIÁN, J. L. (2001): Manual de Arte prehistórico. Barcelona.

SARMIENTO FRADERA, G. (1992): Las primeras sociedades jerárquicas, Instituto Nacional de Antropología e Historia de México.

SHEE TWOHIG, E. (1981): The Megalithic Art of Western Europe. Oxford.

__ (1997): «"Megalithic Art" in a settlement context: Skara Brae and related sites in the Orkney Islands», Brigantium 10: 377-389. 
168 ROSARIO CABRERO GARCÍA / ANA PAJUELO PANDO / EZEQUIEL GÓMEZ MURGA / PEDRO M. LÓPEZ ALDANA
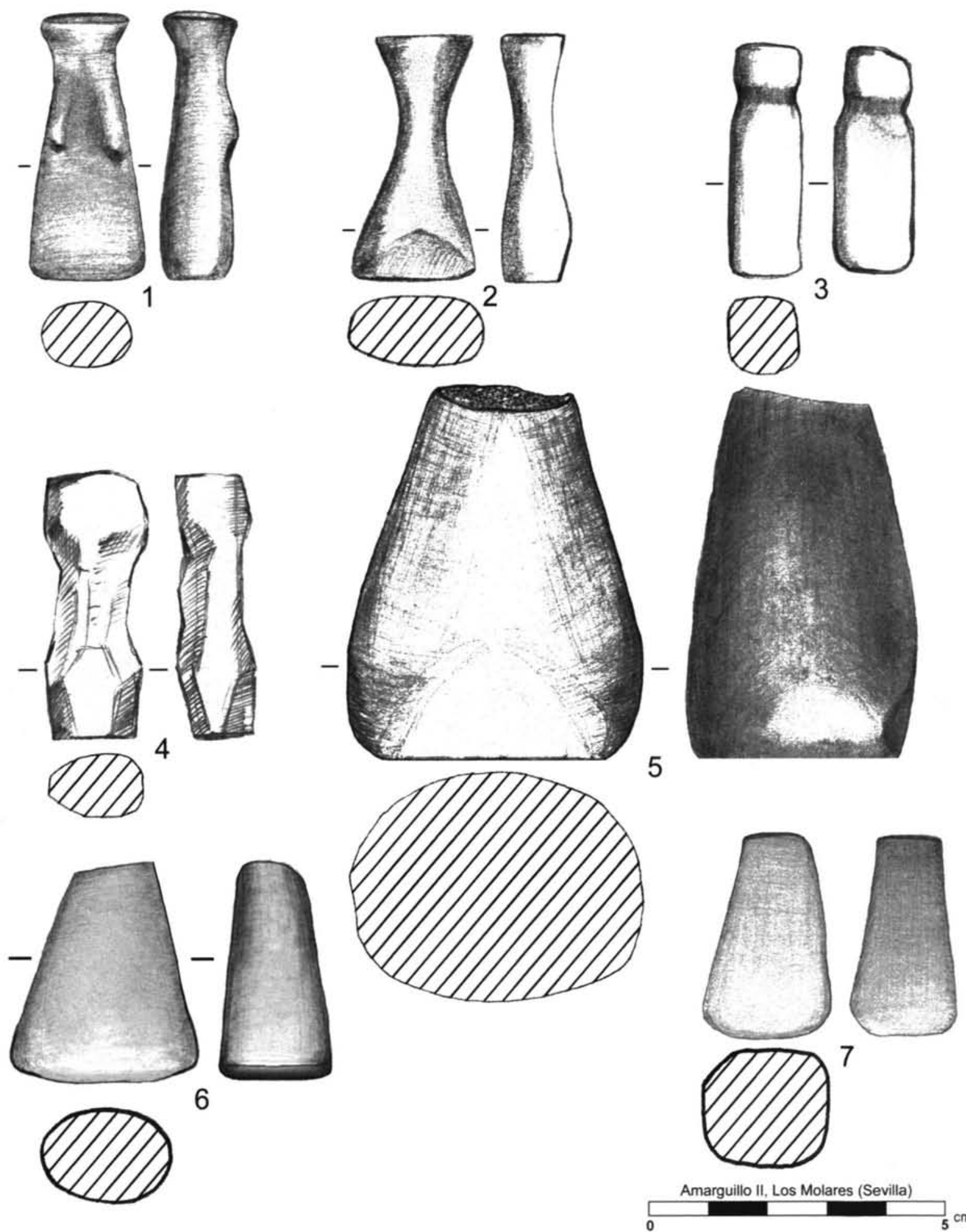

Amarguillo II, Los Molares (Sevilla)

Lámina I

SPAL 12 (2003)

ISSN: 1133-4525 ISSN-e: 2255-3924 http://dx.doi.org/10.12795/spal.2003.i12.07 
OBJETOS DIVERSOS PROCEDENTES DEL POBLADO CALCOLÍTICO DE AMARGUILLO II (LOS MOLARES, SEVILLA) 169
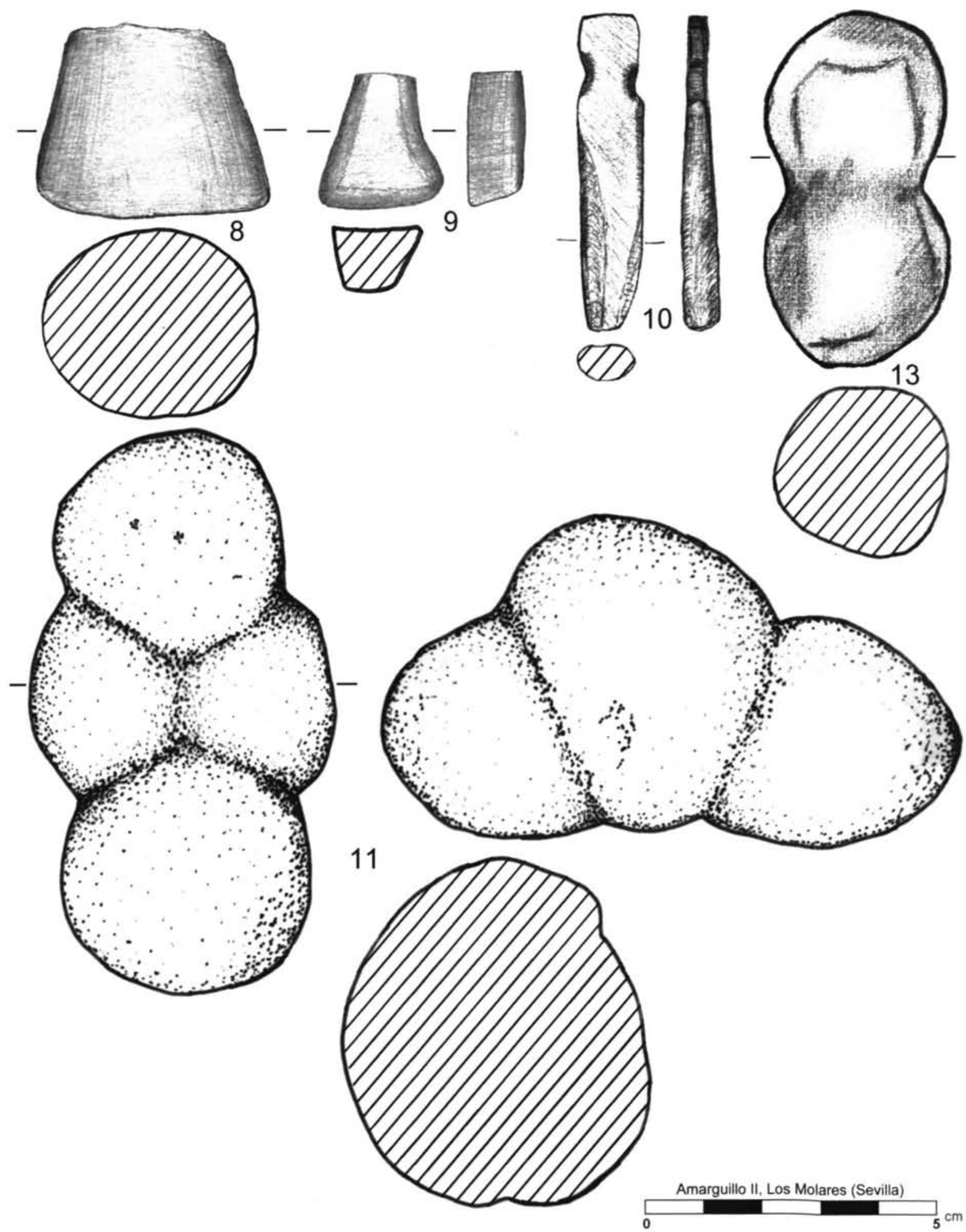

Lámina II

ISSN: $1133-4525$ ISSN-e: $2255-3924$

SPAL $12(2003)$

http://dx.doi.org/10.12795/spal.2003.i12.07 


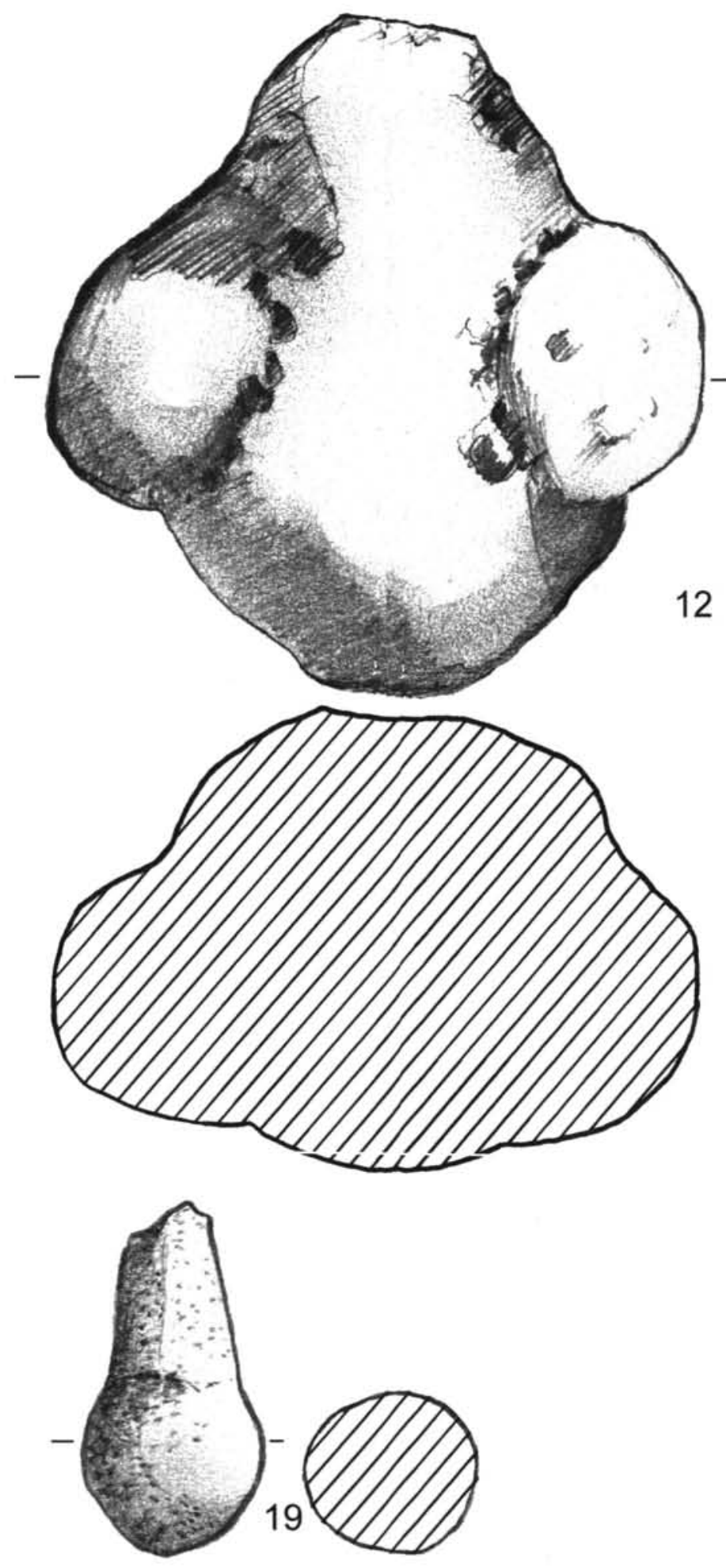

Lámina III

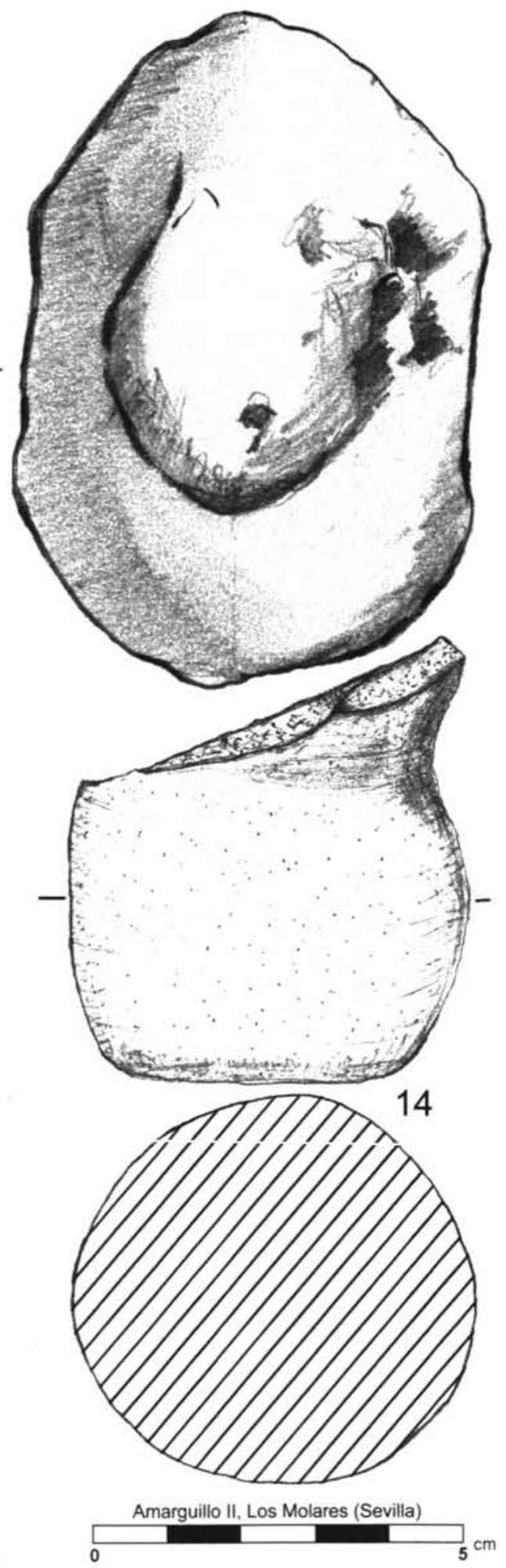



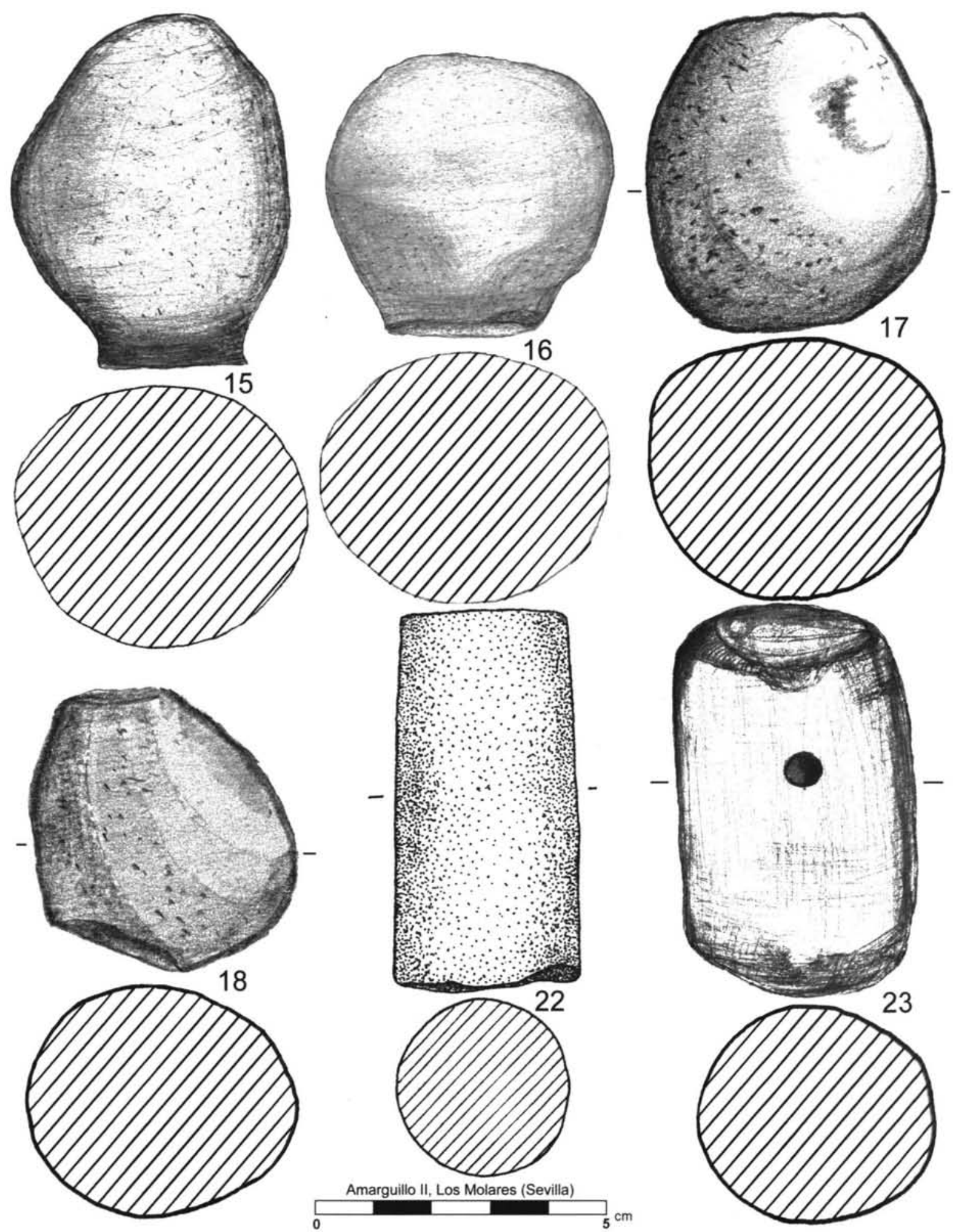

Lámina IV

ISSN: 1133-4525 ISSN-e: 2255-3924

SPAL 12 (2003)

http://dx.doi.org/10.12795/spal.2003.i12.07 

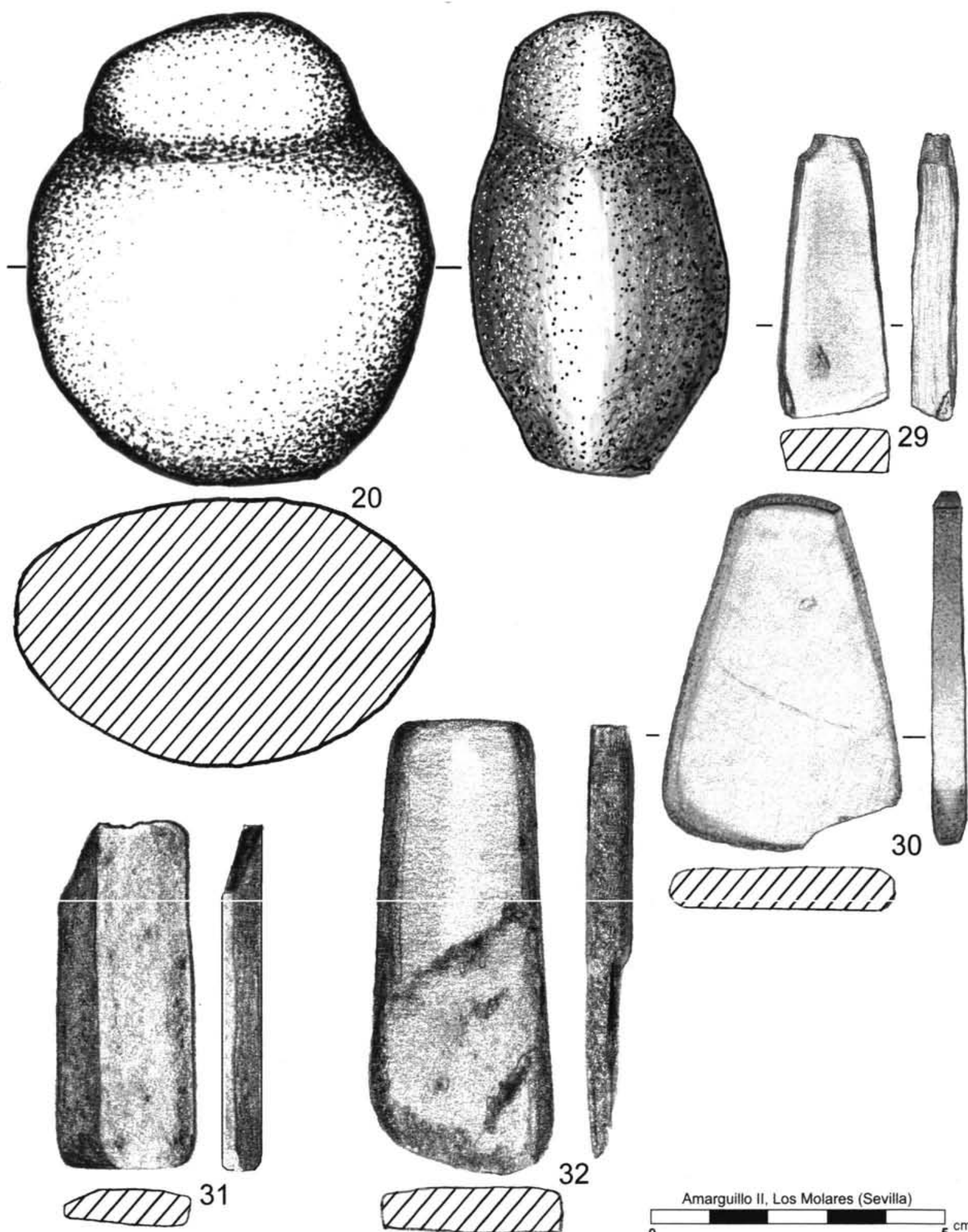

20
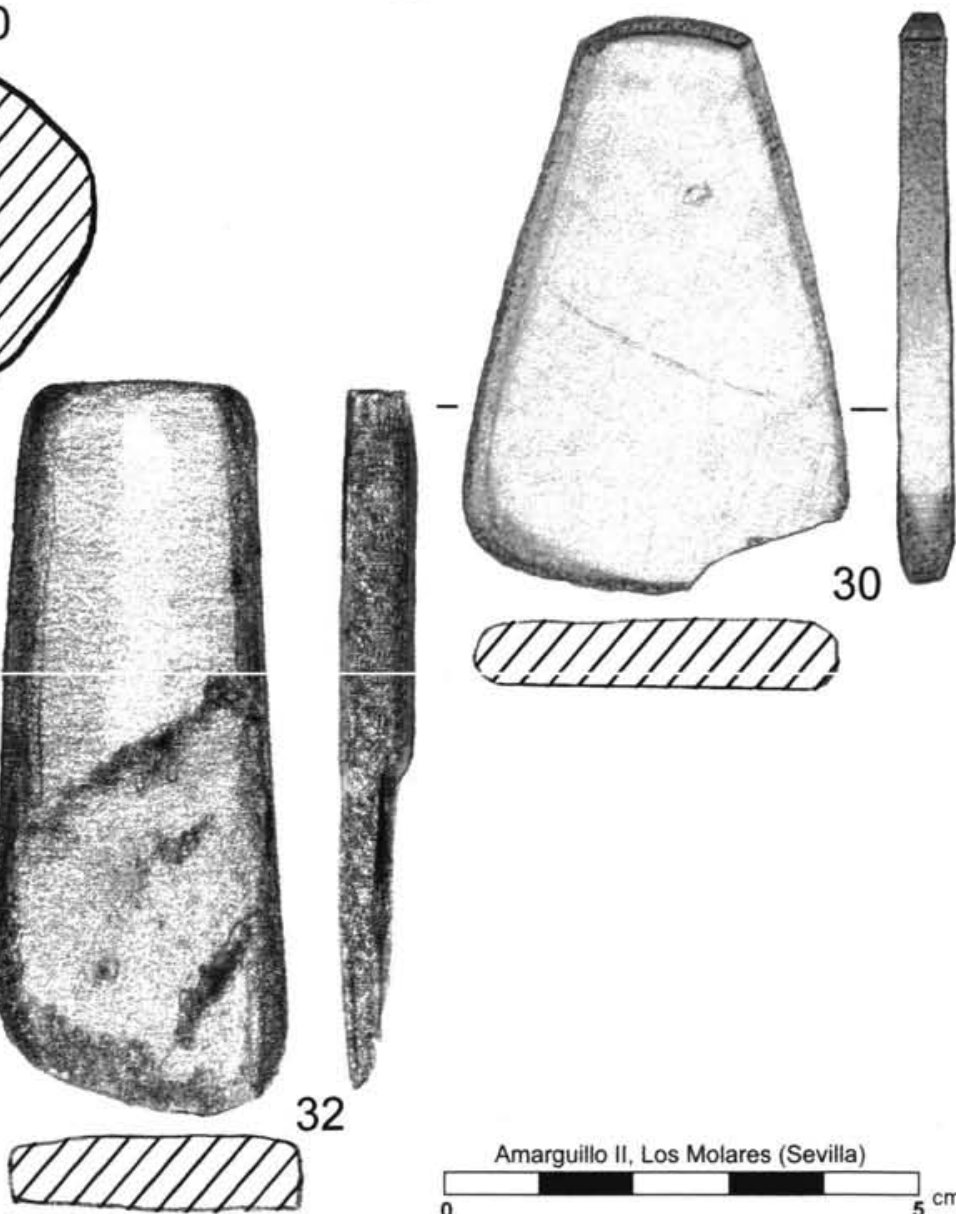

Lámina V 

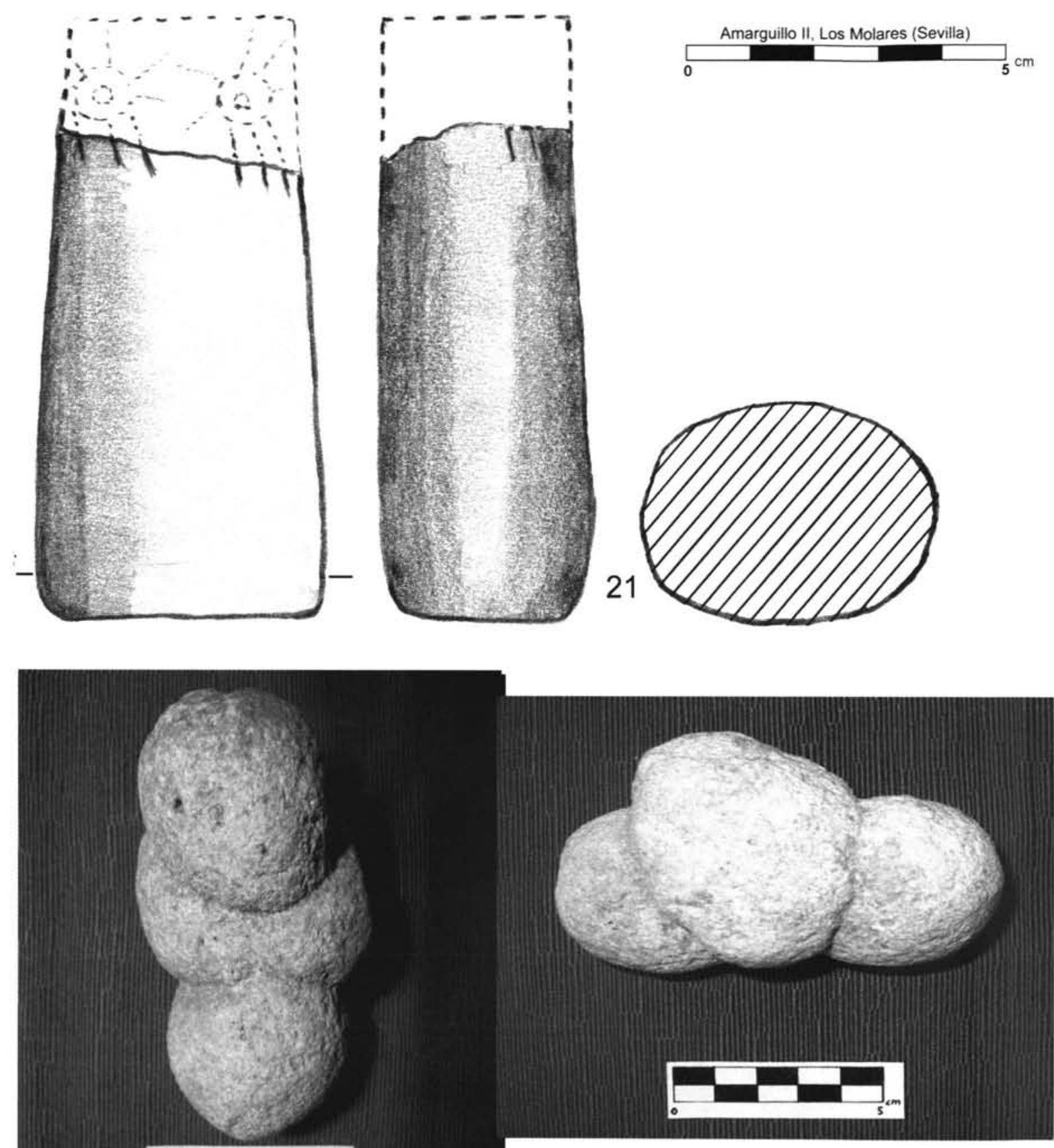

Fotografía de la pieza 11

Lámina VI

ISSN: 1133-4525 ISSN-e: 2255-3924

SPAL 12 (2003)

http://dx.doi.org/10.12795/spal.2003.i12.07 

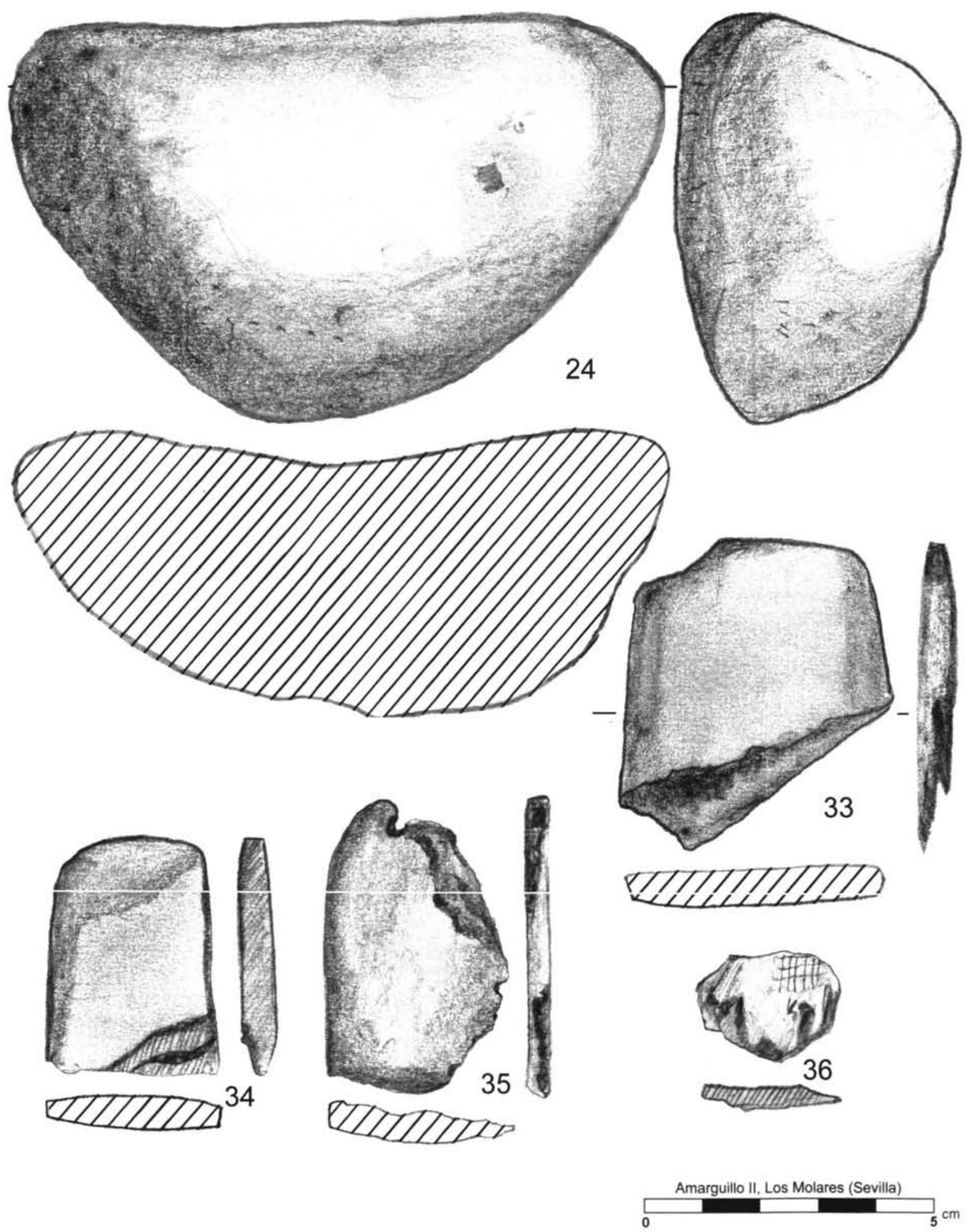

Lámina VII 
OBJETOS DIVERSOS PROCEDENTES DEL POBLADO CALCOLÍTICO DE AMARGUILLO II (LOS MOLARES, SEVILLA) 175
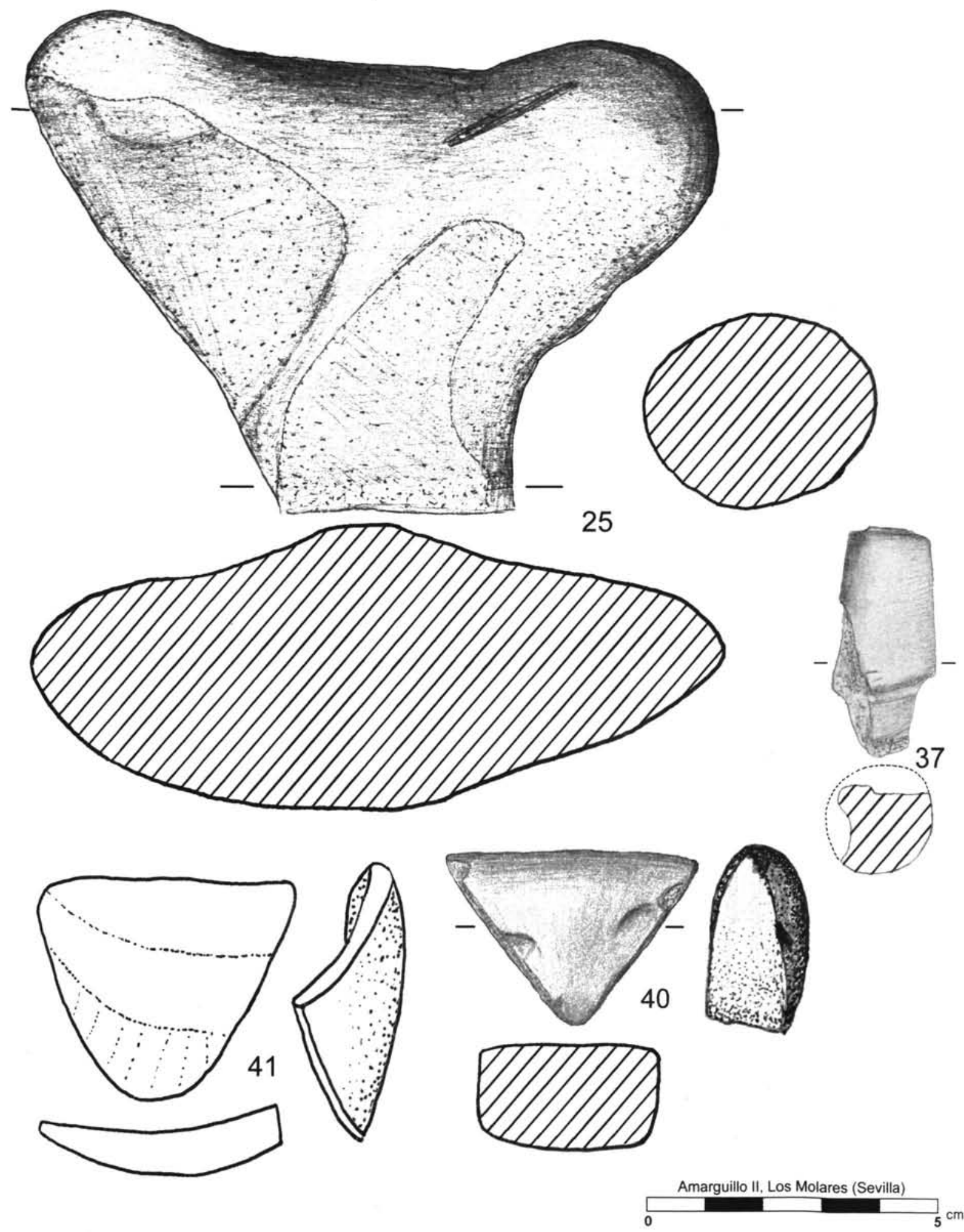

Lámina VIII

ISSN: 1133-4525 ISSN-e: 2255-3924

SPAL 12 (2003)

http://dx.doi.org/10.12795/spal.2003.i12.07 

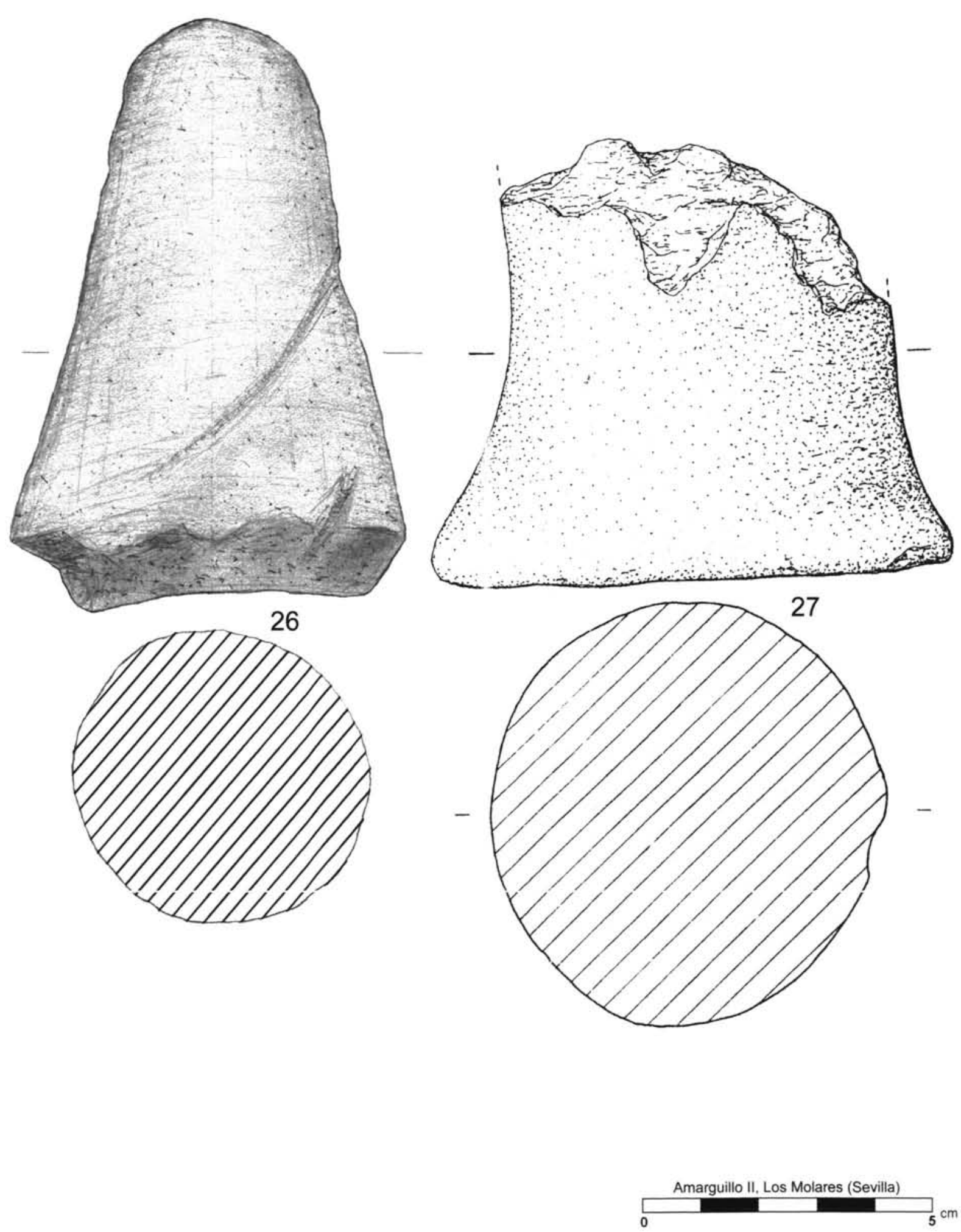

Lámina IX 

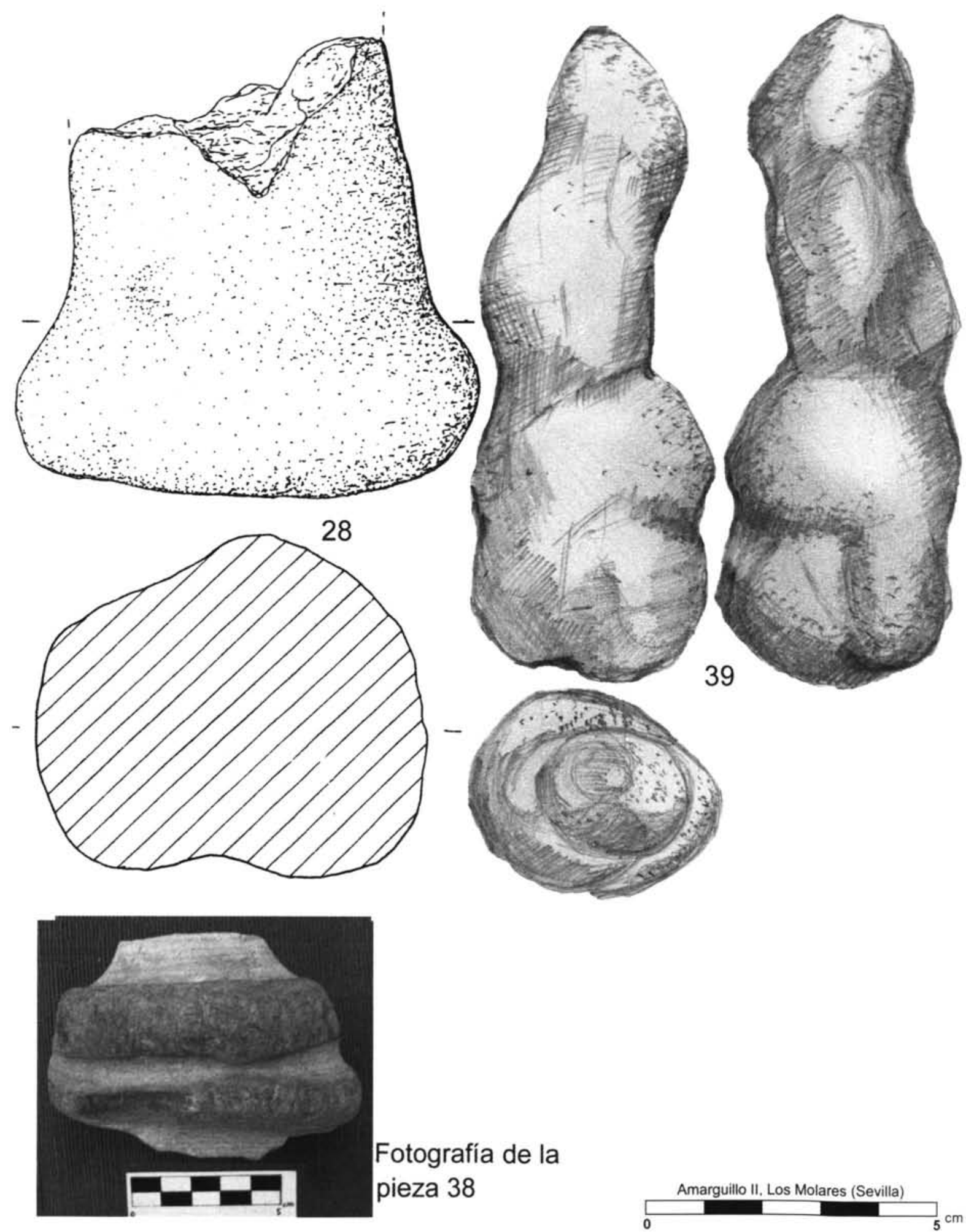

Lámina X

ISSN: 1133-4525 ISSN-e: 2255-3924

SPAL 12 (2003)

http://dx.doi.org/10.12795/spal.2003.i12.07 

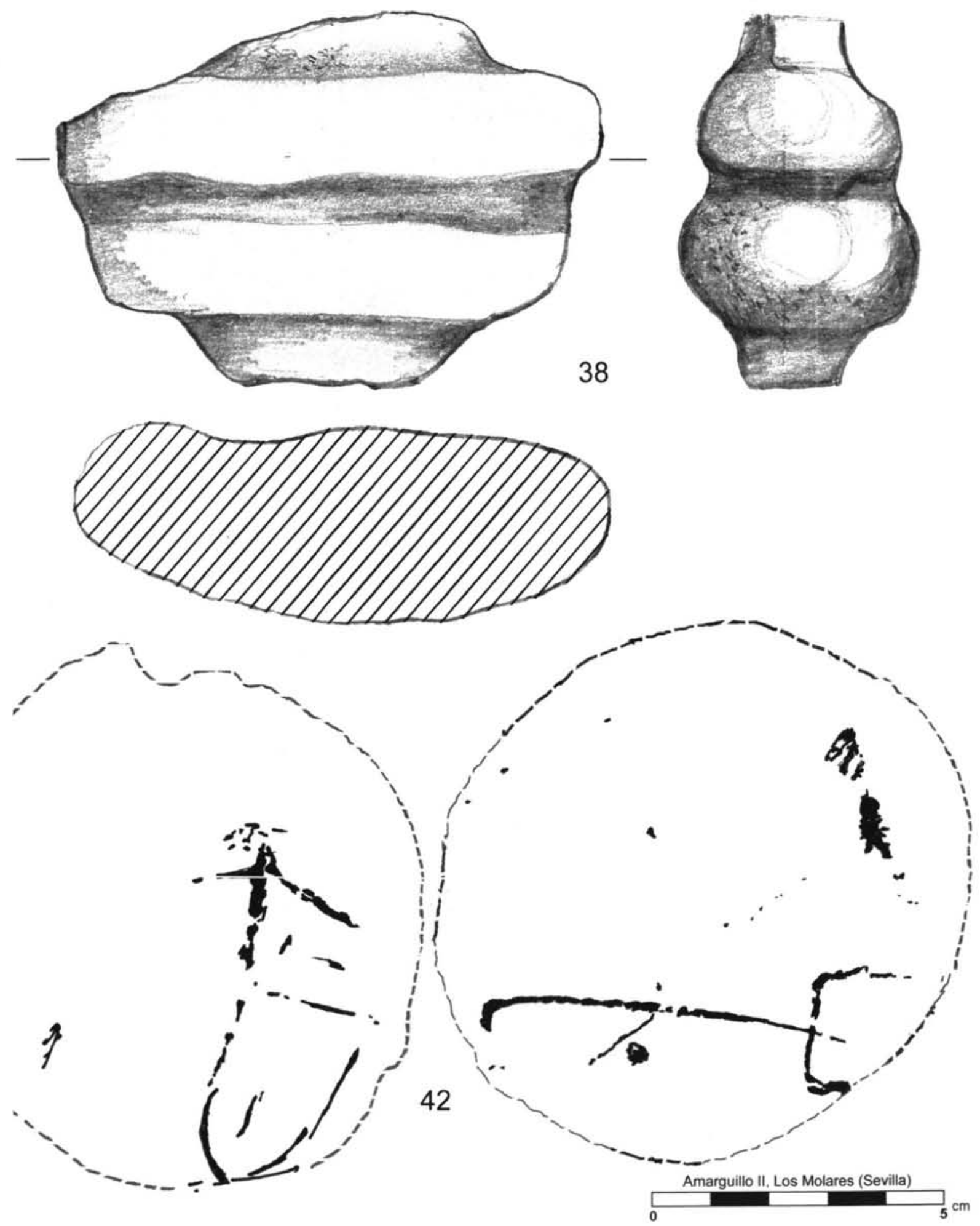

Lámina XI 